\title{
Multiple system atrophy-associated oligodendroglial protein p25a stimulates formation of novel a-synuclein strain with enhanced neurodegenerative potential
}

\author{
Nelson Ferreira ${ }^{1}$. Hjalte Gram ${ }^{1} \cdot$ Zachary A. Sorrentino $^{2}$ - Emil Gregersen ${ }^{1}$. Sissel Ida Schmidt ${ }^{3}$. Lasse Reimer ${ }^{1}$. \\ Cristine Betzer $^{1}$ - Clara Perez-Gozalbo ${ }^{1} \cdot$ Marjo Beltoja $^{1} \cdot$ Madhu Nagaraj $^{4} \cdot$ Jie Wang $^{4,5} \cdot$ Jan S. Nowak $^{4}$.

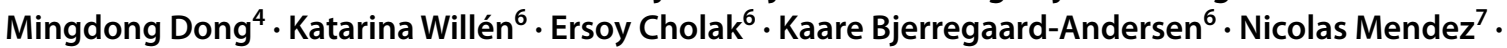 \\ Prakruti Rabadia ${ }^{7}$. Mohammad Shahnawaz ${ }^{7}$. Claudio Soto ${ }^{7}$. Daniel E. Otzen ${ }^{4}$. Ümit Akbey ${ }^{4,8,9} \cdot$ Morten Meyer $^{3,10}$. \\ Benoit I. Giasson ${ }^{2} \cdot$ Marina Romero-Ramos ${ }^{1} \cdot$ Poul Henning Jensen $^{1}$ (D)
}

Received: 26 October 2020 / Revised: 20 April 2021 / Accepted: 21 April 2021 / Published online: 12 May 2021

(c) The Author(s) 2021

\begin{abstract}
Pathology consisting of intracellular aggregates of alpha-Synuclein ( $\alpha$-Syn) spread through the nervous system in a variety of neurodegenerative disorders including Parkinson's disease, dementia with Lewy bodies, and multiple system atrophy. The discovery of structurally distinct $\alpha$-Syn polymorphs, so-called strains, supports a hypothesis where strain-specific structures are templated into aggregates formed by native $\alpha$-Syn. These distinct strains are hypothesised to dictate the spreading of pathology in the tissue and the cellular impact of the aggregates, thereby contributing to the variety of clinical phenotypes. Here, we present evidence of a novel $\alpha$-Syn strain induced by the multiple system atrophy-associated oligodendroglial protein p25 $\alpha$. Using an array of biophysical, biochemical, cellular, and in vivo analyses, we demonstrate that compared to $\alpha$-Syn alone, a substoichiometric concentration of $\mathrm{p} 25 \alpha$ redirects $\alpha$-Syn aggregation into a unique $\alpha$-Syn $/ \mathrm{p} 25 \alpha$ strain with a different structure and enhanced in vivo prodegenerative properties. The $\alpha$-Syn/p25 $\alpha$ strain induced larger inclusions in human dopaminergic neurons. In vivo, intramuscular injection of preformed fibrils (PFF) of the $\alpha$-Syn/p25 $\alpha$ strain compared to $\alpha$-Syn PFF resulted in a shortened life span and a distinct anatomical distribution of inclusion pathology in the brain of a human A53T transgenic (line M83) mouse. Investigation of $\alpha$-Syn aggregates in brain stem extracts of end-stage mice demonstrated that the more aggressive phenotype of the $\alpha-\operatorname{Syn} / \mathrm{p} 25 \alpha$ strain was associated with an increased load of $\alpha$-Syn aggregates based on a Förster resonance energy transfer immunoassay and a reduced $\alpha$-Syn aggregate seeding activity based on a protein misfolding cyclic amplification assay. When injected unilaterally into the striata of wild-type mice, the $\alpha$-Syn/ p25 $\alpha$ strain resulted in a more-pronounced motoric phenotype than $\alpha$-Syn PFF and exhibited a "tropism" for nigro-striatal neurons compared to $\alpha$-Syn PFF. Overall, our data support a hypothesis whereby oligodendroglial p25 $\alpha$ is responsible for generating a highly prodegenerative $\alpha$-Syn strain in multiple system atrophy.
\end{abstract}

Keywords A-Synuclein $\cdot \mathrm{P} 25 \alpha \cdot$ Tubulin polymerisation-promoting protein (TPPP) $\cdot$ Strains $\cdot$ Multiple system atrophy (MSA) $\cdot$ Protein aggregation

\section{Introduction}

Multiple system atrophy (MSA), along with Parkinson's disease (PD) and dementia with Lewy bodies (DLB) are progressive neurodegenerative disorders. They share the

Nelson Ferreira

nelson@biomed.au.dk

Poul Henning Jensen phj@biomed.au.dk

Extended author information available on the last page of the article development of intracellular inclusions containing aggregates of the nerve cell protein alpha-Synuclein ( $\alpha$-Syn) and are often collectively referred to as synucleinopathies [31]. $\alpha$-Syn is a small presynaptic protein involved in SNARE complex functionality and synaptic vesicle release $[12,101]$. 
In synucleinopathies, $\alpha$-Syn turns into insoluble aggregated species hyperphosphorylated on serine 129 that deposits in cytoplasmic inclusions [2, 26]. $\alpha$-Syn is considered a key player in the synucleinopathies, because missense mutations and gene multiplications in the SNCA gene cause autosomal dominant familial PD and DLB, and GWAS studies demonstrate variations in the $\alpha$-Syn-encoding SNCA locus, which is a risk factor for PD [40]. The pathology of synucleinopathies is hypothesised to be spreading through the nervous tissue by native $\alpha$-Syn turning into aggregated prion-like species that upon spreading from one cell to a recipient cell templates the native $\alpha$-Syn into toxic aggregates that can perpetuate the process $[11,47,56]$. Experimental evidence supports this hypothesis by demonstrating that inoculation of $\alpha$-Syn aggregate-containing extracts from animals, patient brains, and in vitro preformed $\alpha$-Syn fibrils (PFF) into the nervous system of laboratory animals initiates aggregation of endogenous $\alpha$-Syn in nerve cells and subsequent spreading of $\alpha$-Syn pathology into anatomically connected areas $[23,61,62,105]$.

MSA has a faster disease progression than other synucleinopathies and differs from them pathologically [97]. In PD and DLB, $\alpha$-Syn aggregates accumulate in Lewy bodies (LB) that reside in $\alpha$-Syn-expressing neurons $[31,66]$. This contrast to MSA, where the burden of $\alpha$-Syn aggregates resides in glial cytoplasmic inclusions (GCI) in oligodendrocytes [27, 96], but also accumulates in neurites and neuronal cell bodies [27, 36, 66, 90, 96]. How the large amounts of $\alpha$-Syn accumulate in the oligodendrocytes is still unresolved [17]. An early in situ hybridization study could not demonstrate any expression [70], but a recent qPCR analysis of oligodendrocytes isolated from human brain demonstrated $\alpha$-Syn mRNA in oligodendrocytes [4]. Moreover, oligodendroglial precursor cells and in vitro cultured human and rodent oligodendroglial cells express $\alpha$-Syn mRNA and protein $[18,44,65]$. Treatment of oligodendrocytes and its precursors with exogenous $\alpha$-Syn aggregates increases the low level of endogenous $\alpha$-Syn by templating the formation of stable $\alpha$-Syn aggregates [44, 44, 65], and this has been hypothesised to represent a neuron-oligodendroglial pathway of importance for MSA [43]. MSA brain extracts and in particular the detergent-insoluble fraction containing the $\alpha$-Syn filaments are more potent seeds of $\alpha$-Syn aggregation in cellular and in vivo models $[79,89,108,114,115]$. This potency can be propagated in laboratory animals and is one reason why MSA has been proposed to represent a distinct prion-like disease [79, 108, 114, 115]. Mounting evidence supports that the $\alpha$-Syn aggregation in oligodendrocytes represents the key to MSA brain extracts being potent inducers of $\alpha$-Syn aggregation in disease models [77].

$\alpha$-Syn filaments isolated from MSA brains possess unique structures as demonstrated by cryoelectron microscopy [89], and $\alpha$-Syn aggregates in human GCI and LB can be distinguished by specific antibodies $[65,77]$. The differences observed between the distinct $\alpha$-Syn inclusion types are recapitulated in the aggregates generated in $\alpha$-Syn mouse models overexpressing $\alpha$-Syn in oligodendrocytes compared to mice only expressing $\alpha$-Syn in neurons upon initiation of aggregation by intracranial injection of $\alpha$-Syn PFF [77]. Surprisingly, $\alpha$-Syn-expressing oligodendrocytes were able to phenoconvert LB-like $\alpha$-Syn aggregates to make GCI-like inclusions, but neurons could not phenoconvert GCI-like strains to make LB-like inclusions [77]. This suggests that factors in the oligodendroglial milieu determine how MSAassociated $\alpha$-Syn strains are generated [77]. We hypothesise that the oligodendroglial protein $\mathrm{p} 25 \alpha$, also named tubulin polymerization promoting protein (TPPP), could be one such factor. P25 $\alpha$ in oligodendrocytes converts their low amounts of cellular $\alpha$-Syn into stable, insoluble, and toxic species $[49,50,65]$, and p25 $\alpha$ stimulates aggregation of $\alpha$-Syn in vitro [58]. In MSA, p25 $\alpha$ becomes dyslocalized from myelin and the nucleus into the perinuclear oligodendroglial cytosol prior to the accumulation of $\alpha$-Syn in GCI where the two proteins colocalize [58, 74, 83, 94]. In synucleinopathies, p25 $\alpha$ also accumulates in neurons, whereas in MSA, it occurs in both $\alpha$-Syn-negative and $\alpha$-Syn-positive cytoplasmic and nuclear inclusions [6]. In PD, the two proteins colocalise in some LB [48, 58, 83], thereby increasing the likelihood of aberrant interactions between the two proteins. We hypothesise that the encounter between p25 $\alpha$ and dystopic $\alpha$-Syn in oligodendrocytes and dystopic $\mathrm{p} 25 \alpha$ with $\alpha$-Syn in neurons causes the formation of a special strain of p25 $\alpha$-induced $\alpha$-Syn aggregates, aggregates that are responsible for the rapid and fatal neurodegeneration in MSA.

In the present work, we generated a novel $\alpha$-Syn strain by incubating $\alpha$-Syn in the presence of $\mathrm{p} 25 \alpha$, and compared this $\alpha$-Syn $/ \mathrm{p} 25 \alpha$ PFF to a control $\alpha$-Syn fibril strain made in the absence of p25 $\alpha$. Structurally, the two strains differed on biochemical, biophysical, and structural parameters. Functionally, the p25 $\alpha$ strain was more effective in templating $\alpha$-Syn aggregation in human neuronal stem cell-derived dopaminergic neurons. When inoculated into wild-type and heterozygous A53T- $\alpha$-Syn M83 transgenic mouse models, $\alpha-$ Syn/p25 $\alpha$ PFF templates inclusions with a different morphology during their spreading in the CNS and cause a more rapid disease course.

Analysis of brain stem extracts of end-stage heterozygous A53T- $\alpha$-Syn M83 mice demonstrated an increased amount of aggregates in $\alpha$-Syn/p25 $\alpha$ PFF-injected mice as determined by a Förster resonance energy transfer immunoassay, and is in agreement with the more rapid disease course compared to control $\alpha$-Syn PFF. Surprisingly, we observed a lower level of templating active seeds in the extracts from the $\alpha$-Syn/p25 $\alpha$ PFF-injected mice using a protein misfolding cyclic amplification assay. Our findings suggest that the $\alpha-$ Syn/p25 $\alpha$ aggregates template $\alpha$-Syn with an enhanced 
neurodegenerative potential and demonstrate that $\mathrm{p} 25 \alpha$ is a strong candidate as an oligodendroglial factor responsible for generation of MSA $\alpha$-Syn strains.

\section{Methods}

\section{Production and purification of a-Syn and p25a}

Full-length human wild-type and S129A-mutant $\alpha$-Syn (1-140) proteins were expressed in BL21(DE3)-competent cells and purified as previously described [22, 58]. Briefly, $\alpha$-Syn purification involved dialysis of heat-stable $E$. coli extracts against $20 \mathrm{mM}$ Tris pH 6.5 overnight, followed by ion-exchange chromatography on a Poros HQ50 column (Thermo Fisher Scientific) with a $0-2 \mathrm{M} \mathrm{NaCl}$ gradient in the dialysis buffer. This was followed by an additional reverse phase-high pressure liquid chromatography purification step on a Jupiter C18 column (Phenomenex, Torrance, CA) in $0.1 \%$ trifluoroacetic acid with a $0-90 \%$ acetonitrile gradient. Isolated $\alpha$-Syn was then extensively dialysed against PBS pH 7.4 overnight followed by an additional dialysis step against $20 \mathrm{mM}$ ammonium bicarbonate overnight. The latter dialysis was performed, because it allows the subsequent lyophilization to remove the volatile ammonium bicarbonate and leave pure protein without any salt for storage. The protein concentration was determined by bicinchoninic acid (BCA) protein concentration assay (Pierce). The proteins were subsequently aliquoted, lyophilized, and stored at $-80^{\circ} \mathrm{C}$ until use. The human $\mathrm{p} 25 \alpha$ was expressed in BL21(DE3)-competent cells and purified as previously described [58]. Briefly, the heat-soluble proteins were purified on a Poros HS50 cation exchange column (PerSeptive Biosystems, Foster City, CA) followed by gel filtration on a GF-75 gel filtration column (Amersham Biosciences).

\section{Quantitative a-Syn fibril assembly and sedimentation}

Soluble monomeric wild-type and S129A $\alpha$-Syn $(346 \mu \mathrm{M})$ were assembled in the absence or presence of $\mathrm{p} 25 \alpha$ $(17 \mu \mathrm{M})$ into preformed fibrils (PFF) by incubation at $37{ }^{\circ} \mathrm{C}$ in phosphate-buffered saline $\mathrm{pH} 7.4$ (PBS, Gibco) with continuous shaking at 1050 r.p.m. (Eppendorf Thermotop) for $72 \mathrm{~h}$. The generated PFF were harvested by centrifugation $15,600 \mathrm{~g}$ at $25{ }^{\circ} \mathrm{C}$ for $30 \mathrm{~min}$ and then resuspended in PBS to a concentration of $2 \mathrm{mg} / \mathrm{mL}$, as determined by BCA protein concentration assay (Pierce) using $0.1 \mathrm{M} \mathrm{NaOH}$ as diluent to completely dissociate the PFF. Then, PFF were sonicated for 20 min using a Branson 250 sonifier at $30 \%$ intensity before being aliquoted and frozen at $-80^{\circ} \mathrm{C}$ until use. A fraction of each sample was set aside for K114 fluorometry [14]. The remainder of each sample was centrifuged at $100,000 \mathrm{~g}$ for $20 \mathrm{~min}$. SDS sample buffer (10 mM Tris, pH 6.8, 1 mM EDTA, $40 \mathrm{mM}$ DTT, $1 \%$ SDS, $10 \%$ glycerol) was added to pellets and supernatants, which were heated to $96{ }^{\circ} \mathrm{C}$ for $15 \mathrm{~min}$. Equal volumes of $\alpha$-Syn proteins in the supernatants and pellets were separated by SDS-PAGE; gels were scanned and quantified using Image $\mathbf{J}$ software (National Institutes of Health, Bethesda, MD, USA).

\section{K114 and thioflavin T fluorometry}

To quantify the amount of amyloid formation, samples were monitored by (trans,trans)-1-bromo-2,5-bis-(4-hydroxy) styrylbenzene (K114) or thioflavin T (ThT) fluorometry as described previously [14]. In brief, samples were analysed by incubating a fraction of each sample with K114 $(50 \mu \mathrm{M})$ in $100 \mathrm{mM}$ glycine, $\mathrm{pH} 8.5$, and measuring fluorescence $\left(\lambda_{\mathrm{ex}}=380 \mathrm{~nm}, \lambda_{\mathrm{em}}=550 \mathrm{~nm}\right)$. For ThT analysis, samples were incubated with ThT $(20 \mu \mathrm{M})$ in $90 \mathrm{mM}$ glycine, $0.01 \%$ Triton X-100, $\mathrm{pH} 8.5$, and fluorescence measured $\left(\lambda_{\mathrm{ex}}=450 \mathrm{~nm}, \lambda_{\mathrm{em}}=482 \mathrm{~nm}\right)$. Both ThT and K114 fluorescence were measured with an EnSpire 2300 Multilabel Reader (Perkin Elmer).

\section{Atomic force microscopy (AFM)}

In AFM measurement, muscovite mica was freshly cleaved by tape and used as substrate. PFF, 8 times diluted at a volume of $10 \mu \mathrm{L}$, were deposited on freshly cleaved mica for $30 \mathrm{~min}$. Then, the excess sample was removed, and the mica was rinsed once with Milli-Q water and later dried in ambient condition for $1 \mathrm{~h}$ before measurement. The AFM morphology measurements were completed using an equipment (Multimode 8, Bruker Co., Ltd., USA) in tapping mode with ultra-sharp silicon cantilevers (OMCL-AC160TS-R3; Olympus). During the measurements, the scan rate was set at $1 \mathrm{~Hz}$. Resonant frequency was set at $300 \mathrm{kHz}$. The resolution of all AFM images was $512 \times 512$ pixels.

\section{Transmission electron microscopy (TEM)}

The grids used for measurement were made of copper with 200-400 mesh spacing. Three microliters of PFF ( $2 \mathrm{mg} / \mathrm{ml})$ were placed on the grid for $1 \mathrm{~min}$, and sample excess was then removed using filter paper. Then, each grid was stained with $3 \mu \mathrm{L}$ of staining solution ( $2 \%$ uranyl acetate in water) for $30 \mathrm{~s}$. After the excess sample was removed, grids were washed with Milli-Q water $(3 \times 10 \mu \mathrm{L})$ and allowed to dry at room temperature. Finally, the grids were visualised with a Tecnai EM microscope equipment (Tecnai G2, FEI, USA). 


\section{Circular dichroism (CD)}

Far-UV CD spectra were recorded on a Chirascan-plus CD spectrophotometer (Applied Photophysics, U.K.) using a $1 \mathrm{~mm}$ quartz cuvette at a concentration of $0.4 \mathrm{mg} / \mathrm{ml}$ protein. PFF were sonicated beforehand with a Q500 sonicator (Qsonica, Connecticut) for $10 \mathrm{~s}$ at $20 \%$ intensity, using a $1.6 \mathrm{~mm}$ Microtip Probe. The samples were measured using a step size of $0.5 \mathrm{~nm}, 0.5 \mathrm{~s}$ per point, and $1 \mathrm{~nm}$ bandwidth. For each sample, three spectra were recorded and averaged.

\section{Fourier-transform infrared spectroscopy (FTIR)}

FTIR spectra were recorded on a Tensor 27 FTIR (Bruker, Massachusetts USA). The samples from CD measurements were recycled and spun at $13.5 \mathrm{Kr}$.p.m. for $5 \mathrm{~min}$. Three microliter samples from the bottom of the Eppendorf tubes were resuspended, transferred onto the quartz crystal, and dried gently with nitrogen. Sixty-eight scans were averaged (1000-3998 $\mathrm{cm}^{-1}$, resolution of $2 \mathrm{~cm}^{-1}$ ). OPUS software was used for baseline correction, atmospheric compensation, second-derivate calculation, and spectral normalisation.

\section{Dynamic light scattering (DLS)}

After $\alpha$-Syn sedimentation, PFF were diluted to $2 \mathrm{mg} / \mathrm{ml}$ in sterile PBS pH 7.4 (Gibco) and subjected to ultrasound breakage for 20 min using a Sonifier (Branson 250; 30\% intensity) equipped with a water jacket cooling system to avoid sample overheating. Then, the size distribution profile of PFF in suspension was measured by DLS using a Wyatt DynaPro NanoStar instrument at $25^{\circ} \mathrm{C}$. Data were processed using the Dynamics 7.5.0.17 software package with the solvent (PBS) background signal subtracted from each sample.

\section{Nuclear magnetic resonance spectroscopy (NMR)}

Solid protein samples were packed into $3.2 \mathrm{~mm}$ Bruker rotors, $\sim 10 \mathrm{mg}$. The high-resolution NMR spectra were recorded using a Bruker $950 \mathrm{MHz}$ NMR spectrometer. MAS frequency was set to $13.5 \mathrm{kHz}$ and the samples were temperature regulated at $270 \mathrm{~K}$. Spectra were processed using the Topspin 3.5 processing program. 2D ${ }^{13} \mathrm{C}-{ }^{13} \mathrm{C}$ PDSD spectrum represented in Fig. 2 was recorded with a $20 \mathrm{~ms}$ mixing period and $\sim 5 \mathrm{~ms}$ indirect dimension evolution time. Three seconds of recycle delay was used and 128 transients were acquired. The spectra were processed with a shifted squared sine-bell window function of 3 .

\section{Proteolytic digestion of a-Syn strains}

Parental PFF (G0) were obtained as mentioned above. Second (G1) and third (G2) generations of $\alpha$-Syn or $\alpha$-Syn/ p $25 \alpha$ PFF were made by seeding wild-type $\alpha$-Syn monomers $(69 \mu \mathrm{M}$, in PBS pH 7.4) with $3.5 \mu \mathrm{M}$ of $\mathrm{G} 0$ or $\mathrm{G} 1$ fibrils, respectively. Samples were then incubated for 5 days at $37{ }^{\circ} \mathrm{C}$ under agitation (1050 r.p.m., Eppendorf Thermotop) and then purified as previously described.

PFF digestion: Digestion of $\alpha-S y n$ and $\alpha-S y n / p 25 \alpha$ PFF was performed by incubating PFF $(0.8 \mathrm{mg} / \mathrm{mL})$ with $0,2.5$, 5 , or $20 \mu \mathrm{g} / \mathrm{mL}$ proteinase K (Sigma-Aldrich) in digestion buffer (78 mM NaCl, $12 \mathrm{mM}$ Tris, $6 \mathrm{mM} \mathrm{CaCl}_{2}, \mathrm{pH} 7.8$ ). After $30 \mathrm{~min}$ of incubation at $37^{\circ} \mathrm{C}$ and shaking at 400 r.p.m., the reaction was stopped by addition of $0.02 \mathrm{mM}$ Pefabloc (Sigma-Aldrich) for $10 \mathrm{~min}$. Samples were then processed for gel electrophoresis.

Gel electrophoresis and Western blot: Loading buffer (100 mM Tris- $\mathrm{HCl}, 8 \%$ SDS, 24\% glycerol, $0.02 \%$ bromophenol blue, and $\mathrm{pH} 6.8$ ) was added to the samples $1: 1$; then, samples were denatured at $95{ }^{\circ} \mathrm{C}$ for $2 \times 5 \mathrm{~min}$. After centrifugation for $5 \mathrm{~min}$ at 16,300 r.p.m., the supernatant corresponding to $12 \mu \mathrm{g}$ protein was loaded into $16 \%$ Tricine gels (Novex) or 8-16\% polyacrylamide gels (GenScript). Protein bands were stained with Coomassie Blue (0.25\% Coomassie Brilliant Blue G-250, 40\% EtOH, 10\% acetic acid) or blotted into PVDF membranes using iBlot ${ }^{\circledR}$ 2 Dry Blotting System (Thermo Fischer). The membranes were then fixed with 4\% PFA in PBS for $30 \mathrm{~min}$ and then boiled in PBS for $5 \mathrm{~min}$. After being blocked for $30 \mathrm{~min}$ (TBS, 0.05\% Tween, skimmed milk powder, pH 7.6), membranes were incubated with primary antibodies, mouse monoclonal anti- $\alpha$-Syn Syn-1 (BD Biosciences \#610,787, 1:1000), or mouse monoclonal anti- $\alpha-S y n$ LB509 (abcam \#27,766, 1:1000) ON at $4{ }^{\circ} \mathrm{C}$. Membranes were subsequently incubated with secondary horseradish peroxidase-conjugated anti-mouse (Dako, Denmark) for $1.5 \mathrm{~h}$ at RT. Protein bands were visualised with ECL (GE Healthcare, UK) and image acquisition by Fuji Las-3,000 intelligent dark box (Fujifilm, Japan).

\section{Dot-blot}

Samples were spotted by non-denaturing immuno-dot blot as previously described [53]. Briefly, different amounts of PFF (3.12-100 ng), monomeric $\alpha$-Syn (100 ng), or vehicle (PBS) were dotted directly onto a nitrocellulose membrane using a vacuum filtration system (Bio-Rad BioDot Apparatus). Membranes were incubated with primary antibodies anti- $\alpha$-Syn Syn-1 (BD Biosciences \#610,787, 1:1000), anti-p25 $\alpha$ (produced in house [58], affinity rabbit polyclonal, 1:1000), and aggregate-specific MJF14-6-4-2 (MJF14) (Abcam \#209,538, 1:45,000) and fibril-specific FILA-1 (produced in house [59], 1:1,000). Proteins were visualised using ECL in a Fuji LAS-3000 Intelligent Dark Box (Fujifilm, Japan). 


\section{Cell cultures}

Human iPSC-derived neural stem dopaminergic neurons: Induced pluripotent stem cell (iPSCs)-derived dopaminergic neurons were differentiated for 45 days using a DOPA differentiation kit (XCell Science) [9]. At day 38 of differentiation, neurons were incubated with S129A- $\alpha$-Syn or S129A- $\alpha-S y n / p 25 \alpha$ PFF $(14 \mu \mathrm{g} / \mathrm{ml})$ in cell medium for 24 h. S129A- $\alpha$-Syn PFF was used in the cellular experiments to avoid any pS129- $\alpha$-Syn signal to arise from phosphorylation of the exogenous aggregates. Untreated neurons were included as control. After $24 \mathrm{~h}$, cells were carefully washed in PBS and allowed to grow for an additional 6 days in fresh medium before fixation in 4\% PFA. Two hours prior to fixation, cells were treated with the polo like kinase inhibitor BI2536 $(1 \mu \mathrm{M})$ to remove physiological nuclear pSer129 $\alpha$-Syn immunoreactivity. The coverslips were subjected to immunostaining using primary antibodies against MAP2 (1:2000, Abcam ab92439) and pS129 (mouse monoclonal 11A5 kindly provided by Imago Pharmaceuticals 1:10,000) with the appropriate secondary Alexa Flour antibodies and DAPI. Five random pictures per coverslip were taken using a motorised stage on a Zeiss Observer.Z1 microscope with an X63 objective. Inclusion analyses were performed using ImageJ with inclusion size distributions; small (25-100 pixel $\left.{ }^{2}\right)$, medium (100-300 $\mathrm{pixel}^{2}$ ), and large (>300 $\left.\mathrm{pixel}^{2}\right)$. All inclusions were measured as round objects $>25$ pixel. Average values were taken for all five pictures per coverslip, and six coverslips per group from two independent differentiations $(n=6)$ were presented as mean \pm SEM.

Rat oligodendroglial cell line: OLN-AS7 [80] stably expressing human $\alpha$-Syn was maintained at $37{ }^{\circ} \mathrm{C}$ and $5 \%$ CO2 in DMEM supplemented with $10 \%$ foetal calf serum (FCS), $50 \mathrm{U} / \mathrm{mL}, 50 \mu \mathrm{g} / \mathrm{mL}$ penicillin/streptomycin (pen/ strep), and $0.1 \mathrm{mg} / \mathrm{mL}$ Zeocin to select for $\alpha$-Syn expression. $\alpha$-Syn and $\alpha$-Syn/p25 PFF $(14 \mu \mathrm{g} / \mathrm{ml})$ were added to the cell medium for $12 \mathrm{~h}$ to allow PFF uptake and intracellular templating. Then, cells were carefully washed trice with Hank's balanced salt solution (HBSS) to remove excess PFF, and fresh medium was added. Cells were allowed to grow for $36 \mathrm{~h}$ before being washed and fixed in 4\% PFA and processed for ICC staining. The coverslips were subjected to immunostaining using primary antibodies against tubulin (1:5000, Abcam \#ab6160) and pSer129 $\alpha$-Syn (1:1000, Cell Signaling Technology \#23,706) with the appropriate secondary Alexa Flour antibodies and 4',6-diamidino-2-phenylindole (DAPI) (1:1000, Th.Geyer, $5 \mathrm{mg} / \mathrm{mL}$ ). Ten pictures/ coverslip were taken randomly using a motorised stage on a Zeiss Observer.Z1 microscope. Inclusion analyses were performed using ImageJ.

In vivo induction and transmission of $\alpha$-Syn pathology by intramuscular injection of $\alpha$-Syn PFF.
Animals, mice treatments, and sample preparations: Animals were housed in a temperature-controlled room under a $12 \mathrm{~h} \mathrm{light/dark} \mathrm{period} \mathrm{with} \mathrm{water} \mathrm{and} \mathrm{food} \mathrm{ad} \mathrm{libitum.} \mathrm{Three-}$ month-old TgM83 ${ }^{+/-} \alpha$-Syn mice were bilaterally injected with $5 \mu \mathrm{l}$ solution $(2 \mathrm{mg} / \mathrm{ml})$ containing $10 \mu \mathrm{g}$ of PFF, or vehicle (PBS, pH 7.4), by inserting the needle $\sim 1 \mathrm{~mm}$ deep into the gastrocnemius muscle as described elsewhere [86]. Mice were anaesthetised with isoflurane $(3.5 \%)$ inhalation. Injections were made using different $10-\mu$ L Hamilton syringes with a 25 -gauge needle to avoid any cross-contamination. Hindlimb clasping behaviour was monitored and scored regularly as previously reported [35, 41]. Once mice displayed hindlimb paralysis, they were sacrificed with pentobarbital euthanization and perfused with PBS with phosphatase inhibitors ( $25 \mathrm{mM} \beta$-glycerolphosphate, $5 \mathrm{mM}$ $\mathrm{NaF}, 1 \mathrm{mM} \mathrm{Na}_{3} \mathrm{VO}_{4}$, and $10 \mathrm{mM}$ Na-pyrophosphate) before removing the brain. Mice injected with vehicle (PBS, $\mathrm{pH}$ 7.4) did not develop any signs of the disease throughout the course of the experiment, and they were sacrificed at 180 d.p.i. Brains were fixed in $4 \%$ PFA in PBS for $48 \mathrm{~h}$, and then stored on $30 \%$ sucrose in PBS with $0.05 \%$ sodium azide solution for IHC tissue processing.

Immunohistochemistry: Immunostaining of the sections was performed using well-established methods [19]. Sections were rehydrated, and subsequent antigen retrieval was performed in a steam bath for $30 \mathrm{~min}$ in a $0.2 \%$ Tween20 solution for all antibodies utilised with the exception of cd11b where a modified citrate buffer (Target Retrieval Solution Citrate pH 6; Agilent, Santa Clara, CA) was used. Non-specific antibody binding was minimised with a $2 \%$ FBS/0.1 M tris block solution; primary antibodies were diluted in block solution and applied to tissue sections at $4{ }^{\circ} \mathrm{C}$ overnight. Biotinylated secondary antibodies (Vector Laboratories; Burlingame, CA) were similarly diluted in block solution and applied to sections for $1 \mathrm{~h}$ at room temperature. An avidin-biotin complex (ABC) system (Vectastain $\mathrm{ABC}$ Elite kit; Vector Laboratories, Burlingame, $\mathrm{CA}$ ) was used to enhance detection of the immunocomplexes, which were visualised using the chromogen 3,3'-diaminobenzidine (DAB kit; KPL, Gaithersburg, MD). For each antibody, all slides were stained and DAB was exposed on the same run with intermixing of slides from each cohort throughout, so that there was no preferential DAB staining of one cohort vs the other in the selective antibodies. Furthermore, in the DAB staining the time to exposure was determined using a control slide, and the experimental slides were not examined until after coverslipping and light microscopy observation. Tissue sections were counterstained with haematoxylin. All slides were digitally scanned using an Aperio ScanScope CS instrument $(40 \times$ magnification; Aperio Technologies Inc., Vista, CA), and images of representative areas of pathology were captured using the ImageScope software $(40 \times$ magnification; Aperio Technologies Inc.). 
Quantitation of 81a and 2H6 positivity was performed on both the brain stem and red nucleus for all cohorts. For each, mouse sections were analysed using the positive pixel count algorithm (Aperio, Leica Biosystems) as described previously [95], with the same intensity threshold values for all sections. One-way ANOVA with multiple comparison was used to determine significant differences $(p<0.05)$.

Antibodies: A panel of antibodies against $\alpha$-Syn phosphorylated at Ser129 including 81A, EP1536Y, and LS4-2G12 was used as previously described [84, 110]. A number of mouse monoclonal N-terminal (1F11, 1D12, 9C10, 2H6, syn506) [15, 20, 109] or C-terminal (94-3A10, 15-4E7, 94-3B2) [15] antibodies of $\alpha$-Syn were also used as they display differing affinities for various types of $\alpha$-Syn inclusions $[15,16]$. Other antibodies utilised for immunohistochemistry included those against p62/sequestosome (ProteinTech), Ubiquitin-1 (EMD Millipore), anti-pThr205 tau antibody 7F2 [100], GFAP (Wako), and cd11b (AbCam).

\section{In vivo induction and transmission of $a-S y n$ pathology by intrastriatal injection of $a$-Syn PFF}

Animals Female C57BL/6 mice (Janvier, $n=59$ ), 6 weeks of age at the time of surgery, were housed six per cage under a $12 \mathrm{~h}$ light $/ 12 \mathrm{~h}$ dark cycle at an average temperature of $21^{\circ} \mathrm{C}$ with ad libitum access to food and water. All procedures involving animals were conducted under humane conditions, were approved by the Danish Animal Experiments Inspectorate (AEI), and complied with Danish laws and regulations for the Humane Care and Use of Animals in Research.

Stereotaxic surgery The animals were deeply anaesthetised with a combination of medetomidine, midazolam, and fentanyl i.p., and then placed in a stereotaxic frame with a mouse/newborn inset (Stoelting, Wood Dale, IL, USA). Two $\mu \mathrm{l}$ solution containing $10 \mu \mathrm{g}$ of $\alpha$-Syn solutions (Monomers $n=19, \alpha$-Syn PFF $n=20$, and $\alpha$-Syn/p25 $\alpha$ PFF $n=20$ ) were injected into the right striatum (coordinates, AP $0.7 \mathrm{~mm}, \mathrm{ML}$ $-2.5 \mathrm{~mm}$ from bregma, and DV $-3.0 \mathrm{~mm}$ from dura), at a rate of $0.2 \mu \mathrm{l} / 30 \mathrm{~s}$, using a glass cannula kept at the target position for another $5 \mathrm{~min}$ and then slowly retracted. The animals were sutured; pain relief was ensured with subcutaneous injection of an anti-sedative mix of naloxone, atipamezole, and flumazenil, and a solution of buprenorphine. When completely awake, the mice were returned to the home cage.

\section{Behavioural tests}

Challenging beam traversal test This test is useful for evaluating motor performance and coordination deficits. It was performed at 3 and 6 months after surgery as previously described [25]. Briefly: the beam consists of four 25-cmlong frames of decreasing width $(3.5,2.5,1.5$, and $0.5 \mathrm{~cm}$, respectively) and a removable grid on top of the beam. Two inverted clean cages are used to support the beam, and the home cage is placed at the narrow end of the beam. Mice were trained to transverse the beam from the widest to narrowest frame for 2 days without the grid on. The trials end when the mouse places one of its forelimbs into the home cage. On the 3rd day, the grid is placed on top of the beam and a video camera is used to record all the trials. All mice transverse the grid surface beam five times. The videos were analysed by an observer, blinded to the animal's identity, recorded time to traverse each frame, time to enter the cage, and errors (paw slips through the grid) and steps in frames 3 and 4. The data used are the average of the five trials.

Cylinder test Mice were tested 3 and 6 months after surgery to evaluate locomotor asymmetry using the cylinder test as described previously [25]. Briefly, the animals are placed in a transparent Plexiglas cylinder (diameter $20 \mathrm{~cm}$ ) with a mirror placed behind it to visualise the cylinder surface fully. A camera is placed in front and adjusted until the whole bottom of the cylinder can be seen in the video from the mirror. Spontaneous use of the animal's forepaws (independently or simultaneously) was video recorded during 3 min or until the number of vertical activity/rearing was 20. The experiment was conducted in a dark room with a red light as the only light source. The videos were analysed by an observer, blinded to the mouse's identity, who recorded right and left forelimb and hindlimb steps. Data are reported as the percentage of contralateral limb use: [(contra $+1 / 2$ both) divided by (ipsi + contra + both)] $\times 100$.

Histology Animals were euthanised by a pentobarbital overdose and upon respiratory arrest, and perfused with physiological saline $(0.9 \%$ saline $)$ through the ascending aorta followed by ice-cold 4\% PFA (50-75 ml per mouse). The brain was carefully removed and post-fixed in the same PFA solution for $2 \mathrm{~h}$ and cryoprotected in a $25 \%$ sucrose solution until processing. The brains were sectioned into $40-\mu \mathrm{m}$-thick serial coronal sections using a freezing microtome (Microm HM 450, Brock\&Michelsen, Denmark) in series of six for the forebrain (striatum) and four for the midbrain, and stored in an antifreeze solution at $-20{ }^{\circ} \mathrm{C}$ until further processing. Immunohistochemical staining was performed on free-floating brain sections using the following primary antibodies: TH (AB152, Rabbit polyclonal, Millipore 1:750), aggregated $\alpha$-Syn (MJF14 (Abcam \#209538, 1:25,000), Iba1 (019-19,741, Wako, Rabbit polyclonal 1:800), GAP (ab7260, Abcam, Rabbit polyclonal, 1:5000), MHC II (14-5321, Rat monoclonal, eBioscience 1:400), and CD68. After incubation with appropriate secondary antibodies, sections were washed and incubated with avidin-biotin-peroxidase complex in KPBS (ABC Elite; Vector Laboratories; Burlingame, CA, USA). The sections were developed using 3,3-diaminobenzidine and $1 \% \mathrm{H}_{2} \mathrm{O}_{2}$. The sections were mounted on gelatine-coated glass slides, 
dehydrated, cleared in xylene, and cover-slipped with DPX (06,522: Sigma-Aldrich, St. Louis, MO, USA).

Microscopy analysis $\mathrm{MHCII}^{+}$cells and cellular structures containing MJF14 ${ }^{+}$misfolded $\alpha$-Syn were quantified at seven coronal sections of the brains using the $20 \times$ lens of a Leica DMI600B microscope, although a complementary morphological analysis was also run at $40 \times$ of magnification when needed. For CD68, one representative photo of $\mathrm{SN}$ at $10 \times$ was taken of each animal; and using Image J, the area covered by immunostaining was calculated for each side and animal.

We performed unbiased stereological quantification of $\mathrm{TH}^{+}$cell bodies in SN based on the optical fractionator principle with an accepted error coefficient of $<0.10$, as described previously [46]. Briefly, stereological counting was performed in sections covering the full extent of SN from the rostral tip of the pars compacta to the caudal pars reticulata (approx. 8-9 sections) using the software NEWcast, Visiofarm (vs. 2.14.11.00). A low-power objective lens $(1.25 \mathrm{x}$, SPlan) was used to outline the borders of the area of interest in SN. The actual counting was performed with an objective at a magnification of 40x, and the step length was changed to achieve at least 100 cells counted.

Statistical analysis All statistical analyses were performed using Prism 7 (Graph Pad software). When appropriate, two-way ANOVA analyses of variance were used to test the interaction between two factors followed by Tukey's post hoc. Comparison of groups was done by one-way ANOVA followed by Tukey's multiple comparison test. Paired analysis was applied for repeated measurements and data originating from the same experimental subject. Values of $* p<0.05$ were considered to be significant. Outliers were removed by Grubb's tests (alpha $=0.05)$. All data were presented as mean \pm standard error of the mean (SEM).

\section{Förster resonance energy transfer (FRET) analysis of aggregated a-Syn}

Aggregated $\alpha$-Syn in mouse brain homogenates was measured with a Förster Resonance Energy Transfer (FRET)based human $\alpha$-Syn aggregation kit (Cisbio Perkin Elmer, 6FASYPEH) according to the vendor's instructions. Aggregated $\alpha$-Syn was detected using one specific monoclonal antibody, labelled either with Tb-Cryptate (donor) or with $\mathrm{d} 2$ (acceptor). When the dyes are in close proximity, the excitation of the donor with a $337 \mathrm{~nm}$ light source triggers FRET, shifting the emission from 620 to $665 \mathrm{~nm}$. Signal intensity is proportional to the number of aggregates in the sample. Briefly, $10 \%$ brain homogenate in PBS was diluted in a twofold dilution series with cisbio lysis buffer, and all dilutions were mixed with Anti-h- $\alpha$-Syn-d 2 antibody and Anti-h- $\alpha$-Syn-Tb-Cryptate antibody in three technical replicates in 384-well plates. After $20 \mathrm{~h}$ incubation at $18-22{ }^{\circ} \mathrm{C}$, fluorescence emission was read at $665 \mathrm{~nm}$ and $620 \mathrm{~nm}$ in PHERAstar micro-plate reader. The $665 / 620$ ratio for each individual well corresponds to the amount of aggregated $\alpha$-Syn. The 64 -fold dilution point was chosen as it was found to be in the linear range of detection. This avoids a hook effect, which is seen at more concentrated dilutions in some homogenates, because too high aggregate concentrations capture all antibodies, leading to a plateau and a decrease in signal. The level of aggregated $\alpha$-Syn in the samples is expressed as delta F\%/ug, which is the percentage of "sample FRET ratio *10,000" compared to the "assay-negative control FRET ratio *10,000" normalised to the protein concentration of the homogenate.

\section{a-Syn protein misfolding cyclic amplification (a-Syn-PMCA) from human A53T-a-Syn-transgenic M83 mice}

The PMCA assay was performed essentially as described [92]. In brief, seed-free C-terminally hexa-histidine-tagged human $\alpha$-Syn $(1 \mathrm{mg} / \mathrm{ml})$ in aggregation buffer $(100 \mathrm{mM}$ PIPES pH $6.5,500 \mathrm{mM} \mathrm{NaCl}$ ) containing $5 \mu \mathrm{M}$ of thioflavin $\mathrm{T}$ (ThT) was placed in an opaque 96-well plate at a final volume of $200 \mu \mathrm{l}$ and incubated in the presence of brain homogenates from vehicle (PBS), $\alpha$-Syn PFF, or $\alpha$-Syn $/ \mathrm{p} 25 \alpha$ PFF IM-injected mice (at final concentrations of $0.01,0.001$, and $0.0001 \%$ ). Samples were subjected to cyclic agitation (1 min at 500 r.p.m. followed by 29 min of no shaking) at $37^{\circ} \mathrm{C}$. The increase in ThT fluorescence was monitored at the $\lambda_{\mathrm{ex}}=435 \mathrm{~nm}$ and $\lambda_{\mathrm{em}}=485 \mathrm{~nm}$, periodically, using a micro-plate spectrofluorometer Gemini-XS (Molecular Devices, Sunnywale, CA).

Proteinase $K$ digestion of PMCA-amplified aggregates PMCA-amplified $\alpha$-Syn aggregates were treated with proteinase $\mathrm{K}(1 \mathrm{mg} / \mathrm{ml})$ for $2 \mathrm{~h}$ at $37{ }^{\circ} \mathrm{C}$. The reaction was stopped by heating the samples in NuPAGE LDS sample buffer at $95{ }^{\circ} \mathrm{C}$ for $10 \mathrm{~min}$. The digested samples were resolved by NuPage 12\% Bis-Tris gel (Invitrogen). Proteins were electrophoretically transferred to a nitrocellulose membrane (Amersham Biosciences). The membrane was blocked with $5 \%$ w/v nonfat dry milk in phosphate-buffered saline-Tween-20 [PBS, 0.1\% (v/v) Tween-20] at room temperature for $1 \mathrm{~h}$. After that, the membrane was probed with Syn-1 antibody (BD Biosciences 610787) (1:5000). The blot was developed using ECL Prime Detection Western Blotting Reagents (Amersham Biosciences).

Preparation of brain homogenates Frozen brain samples were homogenized in $1 \mathrm{X}$ PBS-containing protease inhibitors and phosphatase inhibitors at a final concentration of $10 \%$ using Precellys Lysing Kit (Catalogue no. P000912-LYSK0) in a bead homogenizer at 5000 r.p.m. for 15 s. The brain homogenates were aliquoted and stored at $-80{ }^{\circ} \mathrm{C}$ until analysis. 


\section{Results}

\section{Structural characterisation of p25a-induced a-Syn fibrils}

We hypothesised that the encounter between p25 $\alpha$ and $\alpha$-Syn in oligodendrocytes and neurons in MSA leads to the formation of a structurally distinct and toxic strain of p $25 \alpha$-induced $\alpha$-Syn fibrils, potentially explaining the rapid neurodegeneration in this disease. To test our hypothesis, we first validated the p $25 \alpha$-stimulated $\alpha$-Syn aggregation kinetics in vitro by comparing the aggregation of soluble monomeric $\alpha$-Syn in the absence or presence of substoichiometric amounts of p25 [58]. For monitoring $\alpha$-Syn aggregation, we used a $\alpha$-Syn sedimentation assay (Fig. 1a, b) and thioflavin T (ThT) and K114 amyloid fluorometry (Fig. 1c) [111]. Using sedimentation analysis, we show that in the presence of 5\% p $25 \alpha$ as molar ratio, $\alpha$-Syn aggregates faster than $\alpha$-Syn alone with 70\% compared to $25 \% \alpha$-Syn being insoluble after $24 \mathrm{~h}$ (Fig. 1a, b). Both $\alpha$-Syn strains reached a plateau phase at $48 \mathrm{~h}$, indicating that fibrillation does not proceed further beyond this stage (Fig. 1b). However, the $\alpha$-Syn/p25 $\alpha$ PFF strain comprised a significantly larger fraction of insoluble $\alpha$-Syn than the $\alpha$-Syn PFF strain (94\% vs $84 \%$ ). Thus, the presence of p25 $\alpha$ decreases the amount of soluble $\alpha$-Syn co-existing with fibrils. Once fibrillation has reached a plateau level, it is generally understood that an equilibrium has been established between soluble (monomeric) and insoluble (fibrillated) protein. This equilibrium can be modelled as a simple binding reaction between the monomeric protein and the growing ends of the fibril [7, 72]. Thus, the reduction in soluble $\alpha$-Syn by $\alpha$-Syn/p25 $\alpha$ PFF aggregates indicates that the equilibrium has been displaced towards the fibrillated state compared to the $\alpha$-Syn PFF aggregates.

At the $24 \mathrm{~h}$ time point, all p25 $\alpha$ was found in the insoluble fraction (Fig. 1a) despite approximately $30 \% \alpha$-Syn remaining soluble. The specificity of the interaction of p25 $\alpha$ with the insoluble $\alpha$-Syn was validated by comparing the insoluble fractions of $\alpha$-Syn when aggregated in the presence of $\mathrm{p} 25 \alpha$ and the control proteins carbonic anhydrase (CA) and bovine serum albumin (BSA) (Supplementary Fig. 1a, online resource). Here, it is evident that p25 $\alpha$ is associated with the insoluble $\alpha$-Syn in the pellet fractions in contrast to CA, and BSA remains in the soluble fraction. This highlights how $\mathrm{p} 25 \alpha$ preferentially interacts with aggregated $\alpha$-Syn fibrils, as previously reported [58].

To validate further the specificity of the p $25 \alpha$-induced $\alpha$-Syn aggregation, we compared the aggregation kinetics of $\alpha$-Syn in the presence of $\mathrm{p} 25 \alpha$ and the control proteins CA and BSA. P25 $\alpha$ significantly reduced the lag phase of the aggregation, whereas in the presence of CA and BSA, the lag phase was indistinguishable from aggregation of $\alpha$-Syn alone, as determine by ThT and K114 fluorescence (Supplementary Fig. 1b, c, online resource).

The insoluble aggregates collected after reaching the plateau phase in Fig. $1 \mathrm{~b}$ consisted of pure and intact $\alpha$-Syn (Supplementary Fig. 2a, online resource), and their morphologies were analysed by negative-staining transmission electron microscopic (TEM, Supplementary Fig. 2b, online resource) and atomic force microscopy (AFM, Fig. 1e-h). Both $\alpha$-Syn and $\alpha$-Syn/p25 $\alpha$ PFF presented as twisted, paired, helical filaments, which did not display evident morphological differences to those reported for fibrils [10].

Sonication shears amyloid fibrils into smaller fragments and can be used to assess amyloid nanomechanical properties [1]. Dynamic light scattering (DLS) analysis showed that prolonged sonication of $\alpha$-Syn and $\alpha-S y n / p 25 \alpha$ PFF strains resulted in particle populations of different size distributions. These populations displayed hydrodynamic radii of $49.1 \mathrm{~nm}(\alpha-$ Syn) vs $76.5 \mathrm{~nm}(\alpha-$ Syn/p25 $\alpha)$ (Fig. $1 \mathrm{~d})$. The ability of $\alpha$-Syn/p25 $\alpha$ PFF to withstand ultrasound breakage better than $\alpha$-Syn PFF suggests a reduced structural rigidity.

The fluorescent dye ThT is used extensively to demonstrate the presence of parallel $\beta$-sheet structure in amyloids, and recent evidence demonstrate that its fluorescence can be used to distinguish between $\alpha$-Syn amyloid fibrils amplified by protein misfolding cyclic amplification (PMCA) from CSF from PD and MSA patients [92] where the MSAderived fibrils emit less fluorescence. Figure $1 \mathrm{c}$ demonstrates that $\alpha$-Syn/p25 $\alpha$ PFF emits approximately $50 \%$ of the ThT signal when compared to the control $\alpha$-Syn PFF. This is in contrast with the emission from the PFF-bound K114 dye, which is significantly higher when bound to the $\alpha$-Syn $/ \mathrm{p} 25 \alpha$ PFF. The first-generation $\alpha$-Syn/p25 $\alpha$ strain (G0) induced by $5 \%$ p $25 \alpha$ was propagated in monomeric $\alpha$-Syn by seeding with 5\% $\alpha$-Syn/p25 $\alpha$ PFF for two consecutive generations $(\mathrm{G} 1, \mathrm{G} 2)$. This dilution resulted in a G2 $\alpha-\mathrm{Syn} / \mathrm{p} 25 \alpha$ strain essentially devoid of $\mathrm{p} 25 \alpha$, but with a retained lower ThT fluorescence than the control $\alpha$-Syn PFF (Fig. 2a). Thus, our results indicate that the $\alpha-\operatorname{Syn} / \mathrm{p} 25 \alpha$ strain presents a different packing of its parallel $\beta$-pleated sheet structure, which is propagated in the absence of any p $25 \alpha$ molecules.

Limited proteolysis of amyloid fibrils is a useful technique to distinguish between $\alpha$-Syn strains [10] and proteinase K treatment of $\alpha$-Syn fibrils and $\alpha$-Syn/p25 $\alpha$ PFF resulted in different proteolytic patterns (Fig. 2b). Interestingly, $\alpha$-Syn $/ \mathrm{p} 25 \alpha$ PFF digested with $2.5-5 \mu \mathrm{g} / \mathrm{ml}$ proteinase $\mathrm{K}$ displayed an additional fragment $1 \mathrm{kDa}$ below the band corresponding to the intact protein (arrowhead in red, Fig. $2 b$ ) that was nearly absent in the $\alpha$-Syn PFF samples. Apart from this band, the proteinase-K-treated $\alpha-S y n / p 25 \alpha$ PFF also displayed a series of smaller molecular weight bands upon proteolysis by $20 \mu \mathrm{g} / \mathrm{ml}$ proteinase $\mathrm{K}$ that were absent in the $\alpha$-Syn fibrils. The limited proteolysis allowed 

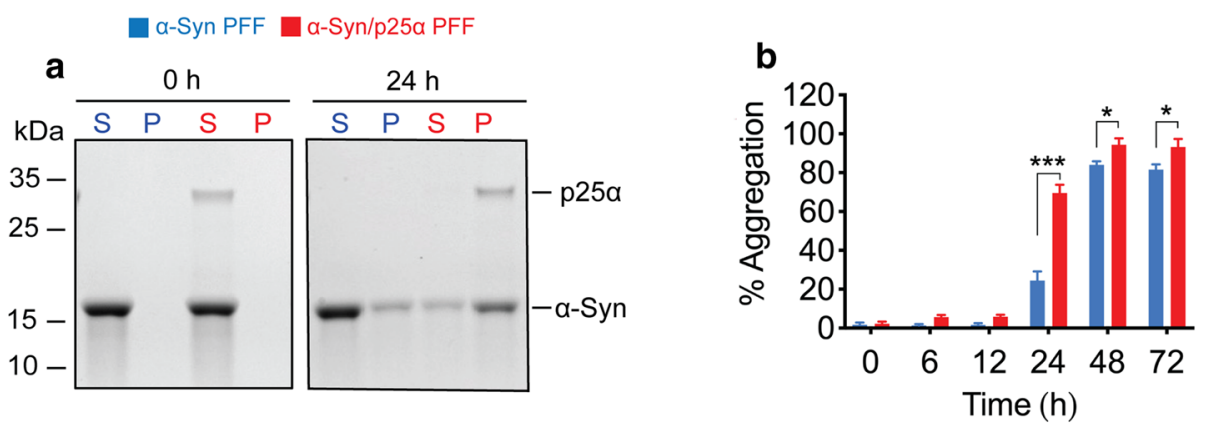

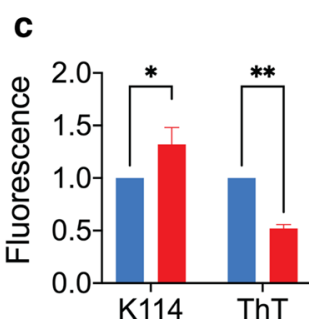

e

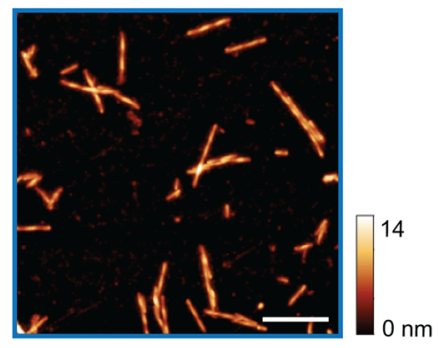

g

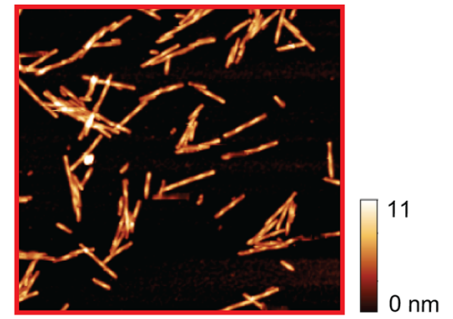

d

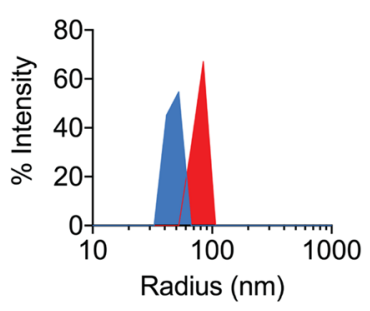

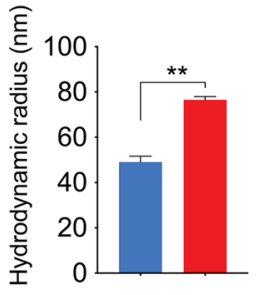

f

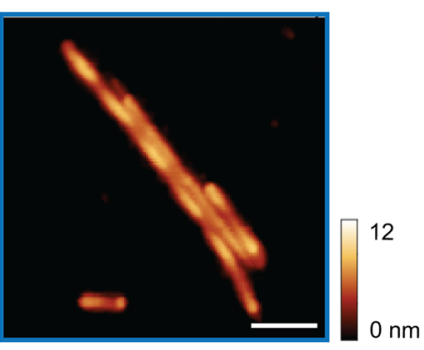

h

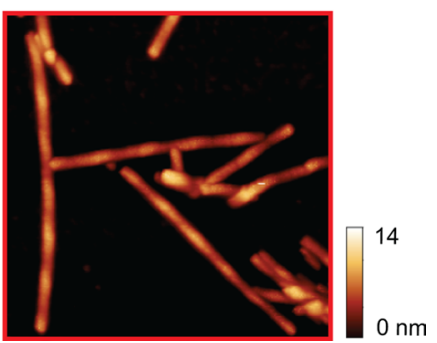

Fig. 1 p $25 \alpha$ accelerates $\alpha$-Syn aggregation and binds to $\alpha$-Syn aggregates. Soluble monomeric $\alpha$-Syn $(346 \mu \mathrm{M})$ was assembled in the absence (labelled blue) and presence of p25 $(17 \mu \mathrm{M})$ (labelled red) into PFF by incubation at $37{ }^{\circ} \mathrm{C}$ with continuous shaking for up to $72 \mathrm{~h}$. During the incubation, samples were removed and analysed for solubility by centrifugation and amyloid formation by K114 and ThT fluorescence. a Representative Coomassie Blue stained SDSpolyacrylamide gel of supernatant $(\mathrm{S})$ and pellet $(\mathrm{P})$ fractions at the beginning of incubation and after $24 \mathrm{~h}$. b Time course for development of insolubility based on densitometric analysis of gels as in panel a. $Y$-axis demonstrates the percentage of aggregation as calculated by $[\mathrm{P} /(\mathrm{P}+\mathrm{S})] \times 100]$. Bars represent as mean $\pm \mathrm{SEM}$ of four experiments. $* P<0.05$; $* * P<0.001$ based on two-way ANOVA followed by Tukey's multiple comparisons test. c K114 and ThT fluores- cence of $\alpha$-Syn and $\alpha$-Syn/p25 $\alpha$ PFF measured at end-stage plateau of aggregation experiment. Y-axis represents arbitrary units normalised to the fluorescence of the control $\alpha$-Syn fibrils. Bars represented as mean \pm SEM of three experiments normalized to $\alpha$-Syn signal. $* P<0.05 ; * * P<0.01$. d Dynamic light scattering (DLS) analysis of $\alpha$-Syn and $\alpha-\operatorname{Syn} / \mathrm{p} 25 \alpha$ PFF aggregates after sonication to shear the filaments. Left panel demonstrates the scattering intensity on the $Y$-axis and the hydrodynamic radius on the $\log$ scaled $X$-axis. The right panel displays the hydrodynamic radius of the two fibril populations displayed as mean \pm SEM of four experiments. $* * P<0.01$ based on two-tailed paired $t$ test. $\mathbf{e}-\mathbf{h}$ Atomic force microscopy (AFM) characterisation of $\alpha$-Syn fibrils (e, f, outlined in blue) and $\alpha$-Syn $/ \mathrm{p} 25 \alpha$ fibrils (g, $\mathbf{h}$, outlined in red). Scale bar in e $=500 \mathrm{~nm}$ also applies to $\mathbf{g}$ and scale bar in $\mathrm{f}=100 \mathrm{~nm}$ also applies to $\mathbf{h}$ 
a

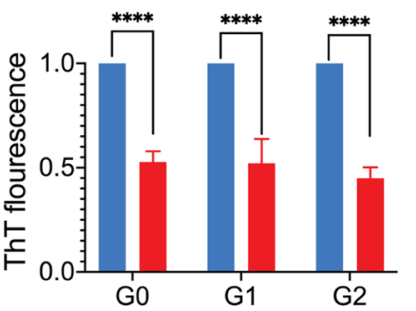

b

a-Syn PFF $\square$ a-Syn/p25a PFF

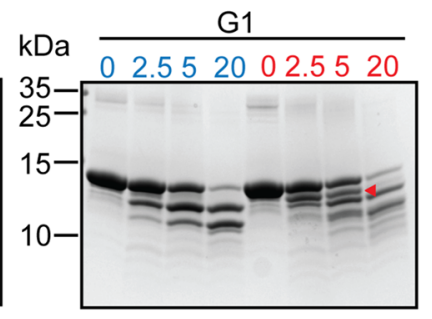

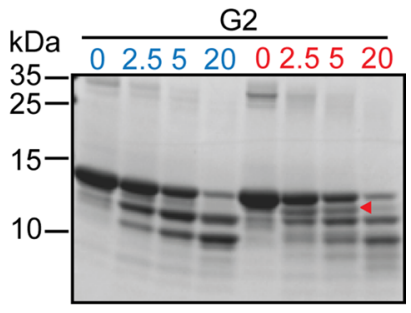

d

e
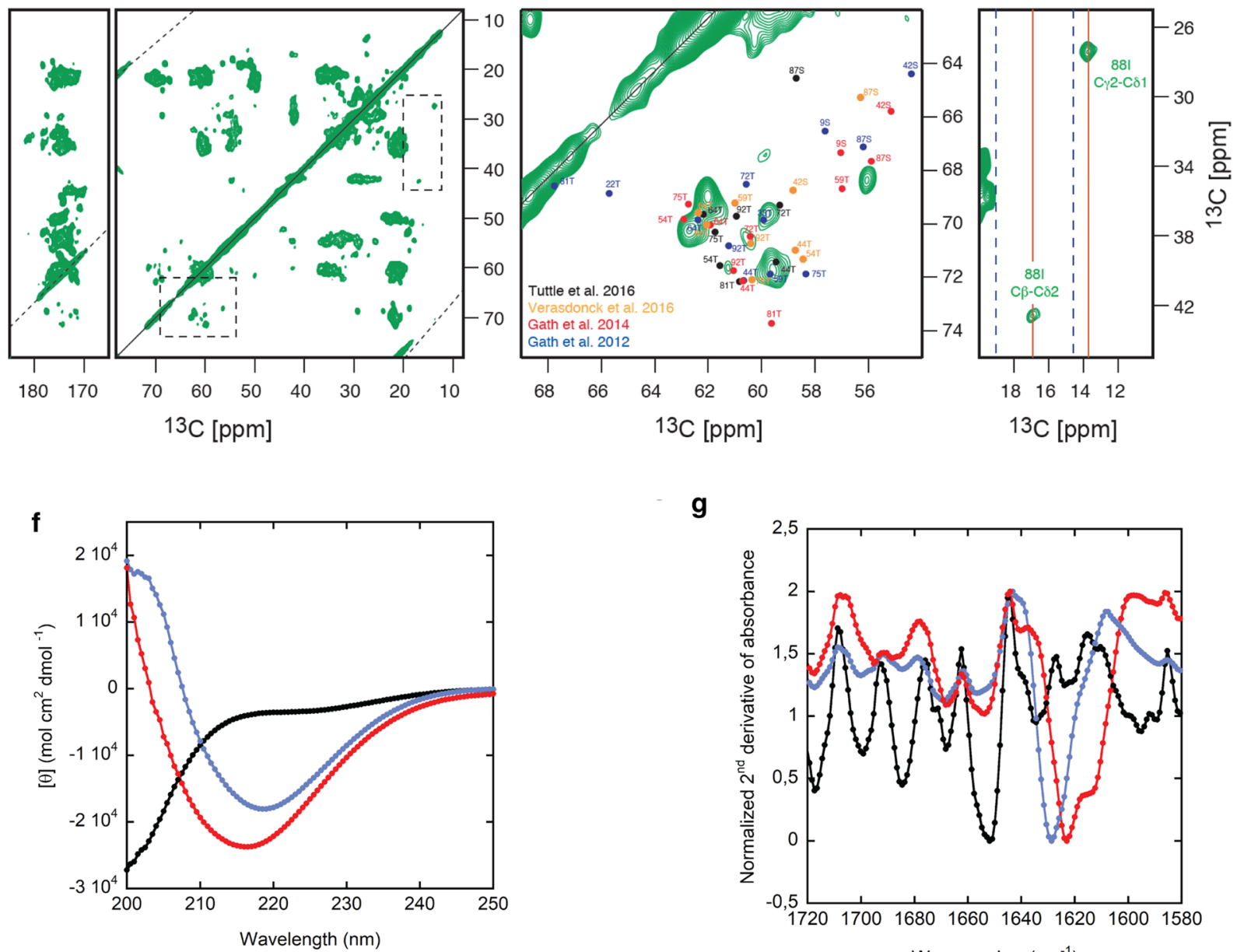

g

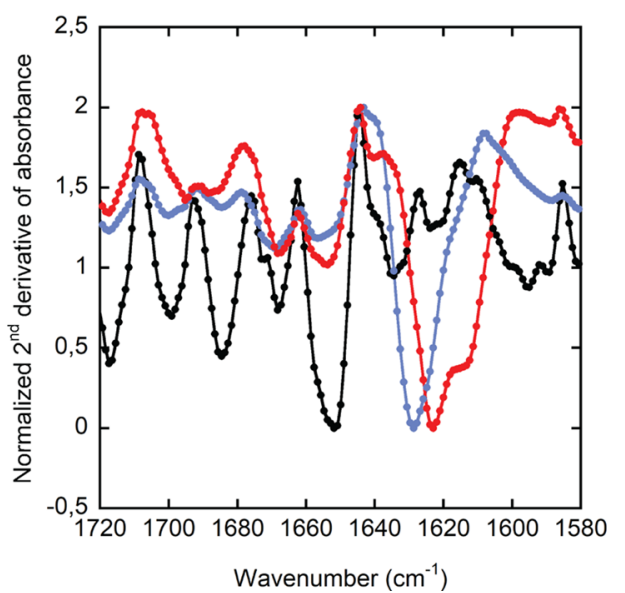

Fig. $2 \alpha$-Syn strains show different structural organisation. De novo generated $\alpha$-Syn and $\alpha$-Syn/p25 $\alpha$ parental PFF (G0) were used to seed second- and third-generation fibrils (G1-G2) by seeding of $69 \mu \mathrm{M} \alpha$-Syn monomers with $3.5 \mu \mathrm{M}$ parental $\alpha$-Syn or $\alpha$-Syn $/ \mathrm{p} 25 \alpha$ PFF as seeds. a ThT fluorescence of G0-G2 of the $\alpha$-Syn and $\alpha$-Syn/ p25 $\alpha$ PFF (blue and red, respectively. Values are normalized to the ThT fluorescence signal of $\alpha$-Syn PFF from the same generation. Asterisks indicate $* * * * P<0.0001$ based on two-way ANOVA followed by Sidak's multiple comparisons test. $\mathbf{b} \alpha$-Syn and $\alpha-\operatorname{Syn} / \mathrm{p} 25 \alpha$ PFF (blue and red, respectively) incubated with increasing concentrations of proteinase $\mathrm{K}$, indicated in $\mu \mathrm{g} / \mathrm{ml}$ above the gels, and resolved by SDS-PAGE followed and Coomassie Blue staining. Molecular size

standards in $\mathrm{kDa}$ are indicated to the left of each gel. The $\mathrm{p} 25 \alpha$ present in the parental $\alpha-S y n / p 25 \alpha$ G0 strain is indicated by red arrow and a prominent $\alpha-\mathrm{Syn} / \mathrm{p} 25 \alpha$ strain-specific proteinase $\mathrm{K}$ fragment that is templated from G0 to G2 is indicated by red arrow head. c Solid-state NMR analysis of $\alpha$-Syn/p25 $\alpha$ PFF. d, e Represents the regions marked with dashed line in panel c. Published chemical shift sets from different structures are inserted in different colours: orange [107], black [103], red [28] and blue [29] presented in d. f Circular dichroism (CD) spectra and $\mathbf{g}$ Fourier-transformed infrared spectroscopy (FTIR) spectra of $0.4 \mathrm{mg} / \mathrm{ml} \alpha$-Syn monomer (black line), $\alpha$-Syn PFF (blue line) or $\alpha$-Syn/p25 $\alpha$ PFF (red line) 
us to demonstrate that the conformational properties of $\alpha-$ Syn/p25 $\alpha$ PFF responsible for the distinct cleavage pattern can be templated into daughter generations in the absence of p25 $\alpha$ analogous to the low ThT fluorescence (Fig. 2a), as determined by Coomassie Blue staining (Fig. 2b) and LB509 antibody binding (Supplementary Fig. 2c, online resource). These findings demonstrate that $\alpha$-Syn/p25 $\alpha$ fibrils can imprint their conformation in newly formed fibrils in the absence of $\mathrm{p} 25 \alpha$.

To investigate further the ultrastructural architecture of this new $\alpha$-Syn $/ \mathrm{p} 25 \alpha$ polymorph, we generated fibrils from ${ }^{13} \mathrm{C}-{ }^{15} \mathrm{~N}$-labelled $\alpha$-Syn followed by solid-state nuclear magnetic resonance (NMR) analysis. The results showed highly ordered and homogenous fibrils, as reflected by sharp and narrow cross-peaks in the $2 \mathrm{D}{ }^{13} \mathrm{C}-{ }^{13} \mathrm{C}$ PDSD spectrum (Fig. 2c-e). A qualitative comparison of the threonine and serine region in the $\alpha$-Syn/p25 $\alpha$ PFF and previously published $\alpha$-Syn polymorphs [28, 29, 103, 107] (Fig. 2d) indicates that $\alpha-$ Syn $/ \mathrm{p} 25 \alpha$ PFF displays a unique amino acid cross-peak pattern that is not fully fitting the hitherto reported $\alpha$-Syn polymorphs. The corresponding chemical shift assignments previously reported, including the socalled "fibril" and "ribbon", are indicated in the spectrum with colour coding in Fig. 2d [28, 29, 103, 107] (summarised in Supplementary Table 1, online resource).

A closer look at the threonine cross-peak region (Fig. 2d) reveals eight cross-peaks that can also be identified in the carbonyl region and NCa spectrum (data not shown). This number nicely corresponds to the number of threonine residues in the fibrillar region. The chemical shift values for the isoleucine, I88, $C \beta-C \gamma 2$, and $C \gamma 2-C \delta 1$ cross-peaks shown in Fig. 2e suggest that the $\alpha-S y n / p 25 \alpha$ PFF resembles the "fibril" conformation rather than the "ribbon" conformation (the corresponding chemical shift values for $88 \mathrm{I}$ in "ribbon" and "fibril" conformations are shown as dashed blue and solid red lines, respectively) [28, 29]. As a result, we hypothesise that in the presence of $\mathrm{p} 25 \alpha, \alpha$-Syn aggregation results in a polymorph varying from previously reported isoforms and more similar to the so-called fibril than the ribbon-type polymorph [10].

Far-UV circular dichroism (CD) (Fig. 2f) and attenuated total reflectance Fourier-transform infrared spectroscopy (ATR-FTIR) (Fig. 2g) were used to evaluate the secondary structure of the $\alpha$-Syn strains. The results indicated that although both $\alpha$-Syn polymorphs show CD and FTIR spectra characteristic of parallel $\beta$-sheet structure, $\alpha$-Syn $/ \mathrm{p} 25 \alpha$ PFF seems more bona fide amyloid. In FTIR spectroscopy, $\beta$-sheets in amyloid fibrils tend to give rise to peaks around $1615-1630 \mathrm{~cm}^{-1}$, while $\beta$-sheets in globular proteins cluster around $1630-1640 \mathrm{~cm}^{-1}$ [117]. The lower the wavenumber, the more "archetypic" the amyloid. $\alpha$-Syn/p25 $\alpha$ PFF showed a minimum around $1623 \mathrm{~cm}^{-1}$, significantly lower than the $1628 \mathrm{~cm}^{-1}$ minimum of $\alpha$-Syn PFF. Further support comes from the observation that the minimum of the CD spectrum was shifted to lower wavelengths for $\alpha-\operatorname{Syn} / \mathrm{p} 25 \alpha$ PFF $(216 \mathrm{~nm})$ than PFF $(219 \mathrm{~nm})$; canonical parallel $\beta$-sheets typically have a minimum around $217 \mathrm{~nm}$ [68].

The surface of $\alpha$-Syn polymorphs has been probed by aggregate-specific FILA-1 antibody, which recognises conformation-specific epitopes in non-denaturing immunodot blot analysis [53, 106] (Supplementary Fig. 2d, online resource). $\alpha$-Syn antibody Syn-1 was used to assure equal loading of the two strains and demonstrated equal binding to the G0 and G1 generation, and p25 $\alpha$ was detectable only in the G0 generation of $\alpha-S y n / p 25 \alpha$ PFF, as expected. The folding of the two strains resulted in an about twofold stronger binding of the polyclonal aggregate-specific FILA-1 [57] to $\alpha$-Syn/p25 $\alpha$ PFF and an enhanced binding of the monoclonal aggregate-specific MJF-14 [53] was also noted (Supplementary Fig. 2d, online resource).

Overall, our results demonstrate that substoichiometric amounts of the oligodendroglial protein p25 $\alpha$ can drive polymerization of $\alpha$-Syn monomers into a novel fibril strain that can be propagated in new generations without the presence of $\mathrm{p} 25 \alpha$.

\section{Seeding of a-Syn aggregation in human iPSCs-derived dopaminergic neurons by a-Syn/p25a fibrils}

To investigate the templated cellular seeding of the two $\alpha$-Syn strains, we differentiated human neural stem cells into dopaminergic neurons using a 45-day protocol $[9,73]$. After 38 days of differentiation, neurons were treated with vehicle, $\alpha$-Syn PFF, or p25 $\alpha$ PFF $(14 \mu \mathrm{g} / \mathrm{ml})$ in cell media for $24 \mathrm{~h}$ to allow uptake of extracellular PFF and intracellular templating. An incubation period of $24 \mathrm{~h}$ was chosen to mimic a "pulse chase" analysis, where a cohort of seeds will initiate a templated aggregation that subsequently deposits in the following 6 days as Ser129- $\alpha$-Syn-positive intracellular inclusions. Excess of exogenous seeds was washed out, and cells were allowed to grow for additional 6 days in fresh medium (Fig. 3). For all cellular experiments, PFF were made using the mutant $\mathrm{S} 129 \mathrm{~A}$, which is nonphosphorylatable at position 129, to allow us to use phosphor-Ser129 as a proxy for aggregation of endogenous intracellular $\alpha$-Syn. The S129A mutant did not affect the p25 $\alpha$-dependent folding of the $\alpha-\operatorname{Syn} / \mathrm{p} 25 \alpha$ strain as determined by proteinase $\mathrm{K}$ cleavage analysis (Supplementary Fig. 3a, online resource).

Our results show that although both strains templated the formation of phosphor-Ser129- $\alpha$-Syn-positive intracellular inclusions in a similar fraction for the cells (Fig. 3a-c), uptake of $\alpha-\operatorname{Syn} / \mathrm{p} 25 \alpha$ seeds induced quantitative changes to the size distribution of inclusions with a significant expansion of especially the population of larger inclusions 

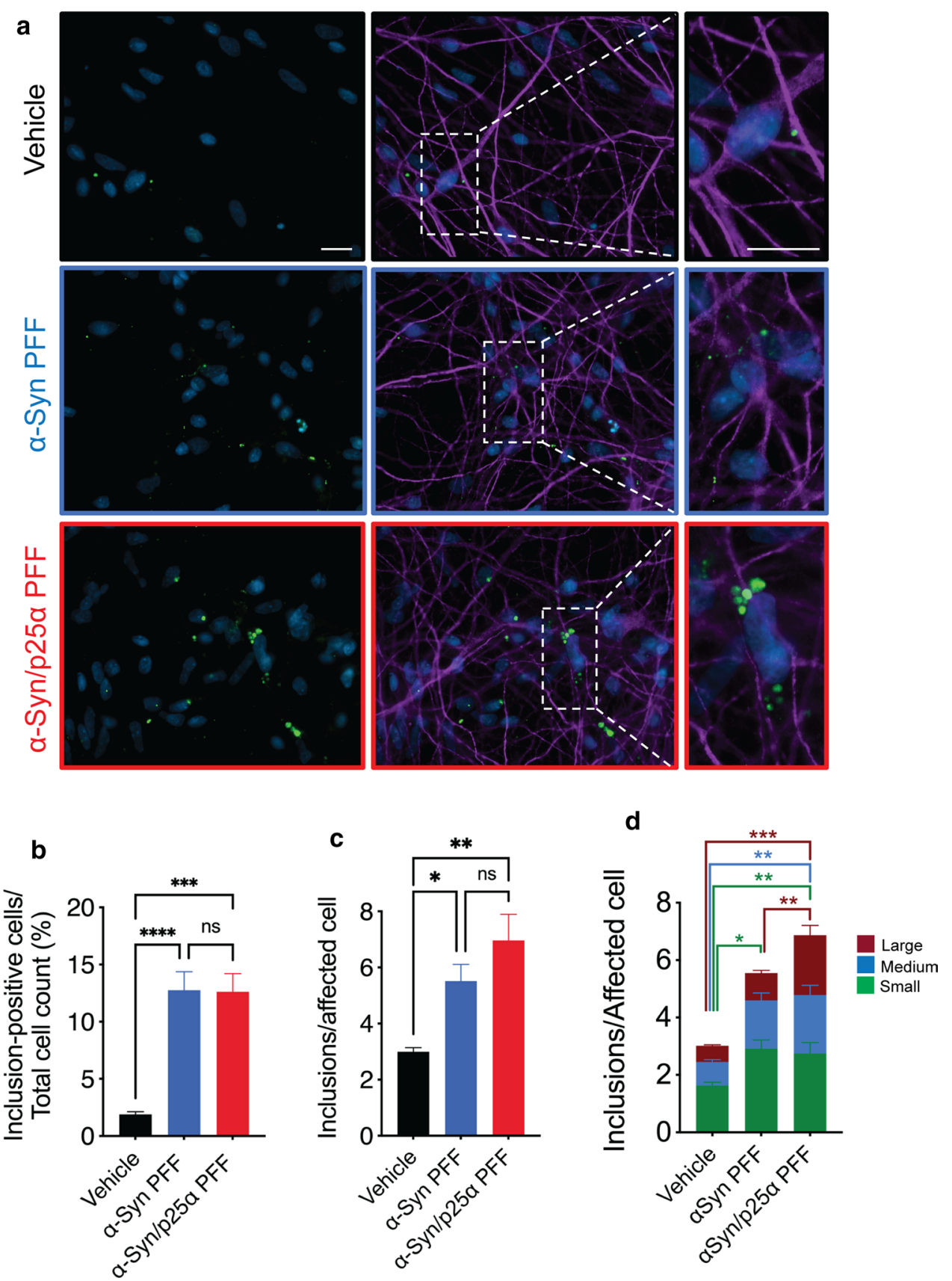

Fig. $3 \alpha$-Syn $/$ p25 $\alpha$ PFF template more and larger $\alpha$-Syn inclusions in human iPSCs-derived neurons. a Human iPSCs-derived neurons were differentiated from neuronal stem cells for 45 days. After 38 days of differentiation, neurons were supplemented with vehicle (upper panels) or G1 generation of $\alpha$-Syn PFF (middle panels, outlined in blue) and $\alpha-S y n / p 25 \alpha$ PFF (lower panels, outlined in red) $(14 \mu \mathrm{g} / \mathrm{ml})$ for $24 \mathrm{~h}$ followed by media shift to remove excess PFF. They were kept in culture for an additional 7 days in fresh medium before fixation in $4 \%$ PFA. Cells were immunostained for microtubule-associated protein 2 (MAP2) (purple) to label neuronal cell bodies and pS129 $\alpha$-Syn (green) to label inclusions, and the nuclei were stained with DAPI (blue). Pictures were taken randomly with a X63 objective on a
Zeiss Observer Z1 microscope. Scalebar $=20 \mu \mathrm{m}$. b Columns demonstrate percentage of total MAP2-positive neurons carrying inclusions. c Columns demonstrate number of pS129- $\alpha$-Syn-positive inclusions/ MAP2 neuron carrying inclusions. d Bar graph illustrating inclusion size distribution categorized into small (25-100 pixel $^{2}$, green), medium (100-300 pixel $^{2}$, blue), and large (>300 pixel $^{2}$, maroon) inclusions for the cells analysed in c. In the two differentiations performed, a total of $n=308$ inclusion-bearing cells were analysed for the $\alpha$-Syn $/ \mathrm{p} 25 \alpha$ PFF group, $n=267$ cells for the $\alpha$-Syn PFF group and $n=189$ cells for the untreated group. Bars represent mean \pm SEM from six different cultures derived from two independent differentiations. $* P<0.05$, $* * P<0.01, * * * P<0.001$ based on one-way ANOVA 
compared to $\alpha$-Syn PFF (Fig. 3d; Supplementary Fig. 3b, online resource).

We did parallel studies using a rat oligodendroglial cell line (OLN-AS7) stably expressing human $\alpha$-Syn that was challenged with $14 \mu \mathrm{g} / \mathrm{ml}$ of the two PFF polymorphs (Supplementary Fig. 3c-g, online resource). These cells were treated for $12 \mathrm{~h}$ with the two strains before being washed and supplemented with fresh cell culture media and incubated for further $36 \mathrm{~h}$, because we aimed for a "pulse chase-like" analysis of mitotic cells that divides approximately every $24 \mathrm{~h}$. Immunofluorescence microscopic analysis demonstrated that $\alpha$-Syn/p25 $\alpha$ PFF-treated OLN-AS7 cells developed larger and more numerous pSer129-positive inclusions than cells incubated with $\alpha$-Syn PFF (Supplementary Fig. $3 \mathrm{c}-\mathrm{g}$, online resource), resembling our observations using human neurons (Fig. 3).

To address if the increased intracellular load of aggregate inclusions is due to an enhanced uptake of the $\alpha$-Syn $/ \mathrm{p} 25 \alpha$ strain or may reflect strain-dependent differences in their templating activity, we used wild-type OLN-93 cells. These cells do not express endogenous $\alpha$-Syn, and this allowed us to study the cellular accumulation of the exogenous $\alpha$-Syn strains being taken up from the medium. Supplementary Fig. $4 a, b$ (online resource) demonstrates that the total $\alpha$-Syn associated with the cells accumulated in inclusionlike puncta that covered similar areas of the cells after 0.5 and $24 \mathrm{~h}$ of incubation for the two strains. This suggests that the cellular uptake and accumulation of $\alpha-S y n$ and $\alpha-S y n /$ p25 $\alpha$ PFF are identical.

Overall, our results demonstrate that once $\alpha-\operatorname{Syn} / \mathrm{p} 25 \alpha$ PFF are within neurons, they recruit endogenous $\alpha-S y n$ into larger cytoplasmatic inclusions than the control $\alpha$-Syn strains. The occurrence of a similar strain-specific handling in a mitotic rat cell-line-expressing human $\alpha$-Syn suggests that this process does not require cell-type-specific factors, but engages core cellular homeostatic machinery. Elucidating the nature of the specific inclusion compartments of the strains will likely require high-resolution analysis.

\section{Propagation and neurodegenerative activity of $a-S y n / p 25 a$ fibrils in vivo}

To determine if the $\alpha$-Syn/p25 $\alpha$ strain holds greater neurodegenerative potential in vivo, we used two mouse models. First, we used a transgenic mouse model expressing the mutant human A53T $\alpha$-Syn controlled by the mouse prion protein promoter (M83 line), and where the $\alpha$-Syn PFF strains are injected into the hindlimb gastrocnemius muscle [86]. This model allows the study of trans-synaptic spreading of $\alpha$-Syn aggregate through the neuraxis with a well-defined lethal end point that allows quantitative death curve analysis to be performed. Second, we used wild-type C57BL/6 mice injected with the $\alpha$-Syn PFF strains in the striatum. This model enables us to determine if the seeding can occur in a model with endogenous $\alpha$-Syn levels, and if the strain-specific spreading from the striatum displays any preference in targeting projecting neurons located in the substantia nigra compared to, e.g., amygdala. Wild-type C57BL/6 mice express endogenous mouse $\alpha$-Syn, whereas M83 mice additionally express human A53T- $\alpha$-Syn driven by the mouse prion promoter. For the sake of consistency, we choose to use human PFF for both the M83 and the wild-type mice, because the effect of p $25 \alpha$ on mouse $\alpha$-Synderived aggregates should otherwise have been characterised and compared to the human $\alpha-\operatorname{Syn} / \mathrm{p} 25 \alpha$ strain. Still, this calls for caution when comparing data on spreading and cytopathology between the two mouse models.

Heterozygous M83 mice $\left(\mathrm{M} 83^{+/-}\right.$) were used, because they do not spontaneously develop disease within the time frame of our experimental design if not inoculated with $\alpha$-Syn PFF. We used the intramuscular (IM) injection of PFF in the hindlimb to induce the lethal disease, because transsection of the sciatic nerve significantly reduced CNS neuroinvasion and prion-like spread of $\alpha$-Syn aggregation [86]. Three-month-old $\mathrm{M} 83^{+/-}$mice were bilaterally injected in the gastrocnemius muscle with $10 \mu \mathrm{g}$ of the PFF strains for each injection. The injection needle was inserted $1 \mathrm{~mm}$ into the muscle, without damaging the sciatic nerve. Our results demonstrate that compared to $\alpha$-Syn PFF-injected mice, the $\alpha-$ Syn/p25 $\alpha$ PFF decreased median survival time by $26 \%$ (Fig. 4a). Using hindlimb clasping as a first sign of detectable disease, we observed that the disease-free period was reduced by $28 \%$ (Fig. 4b), and therefore, the disease phenotype progressed $45 \%$ faster as determined by time from first clasping to death (Fig. 4c). Other behavioural tests, e.g., grip strength, may have identified a different onset of disease, but would likely not have changed the overall conclusion of a faster disease progression. To identify factors in the brain of affected mice that correlate with the enhanced neurodegenerative phenotype, we compared brains from mice challenged with $\alpha$-Syn and $\alpha$-Syn/p25 $\alpha$ PFF at the cellular, histological, and biochemical levels.

Our immunohistochemical analysis of coronal sections of the brain focussed on particular areas on the brainstem, midbrain, and red nucleus (Fig. 4d-g; Supplementary Fig. 5-7, online resource). The DAB staining provides semiquantitative information and was especially useful to characterise the presentation of antigens in the cell bodies. The results showed that, as expected, none of the vehicle-injected (PBS) mice displayed any signs of pathology (Fig. 4e-g; Supplementary Fig. 5, online resource). Immunodetection, using a panel of antibodies to investigate differences in $\alpha$-Syn pathology [15], demonstrated that $\mathrm{N}$-terminal $\alpha$-Syn-specific antibodies (2H6 in Fig. 4g; and 1D12 in Supplementary Fig. 5f, online resource) preferentially detected pathology in the $\alpha-\operatorname{Syn} / \mathrm{p} 25 \alpha$ PFF cohort compared to the control 


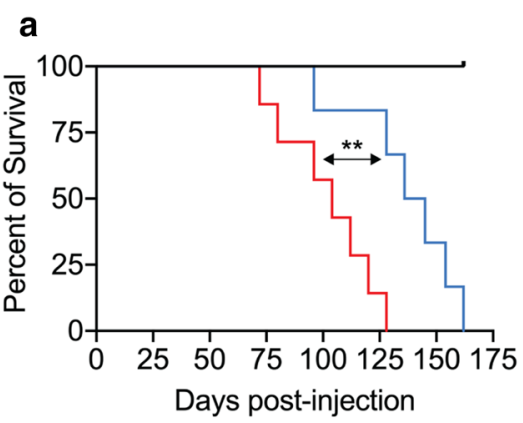

d

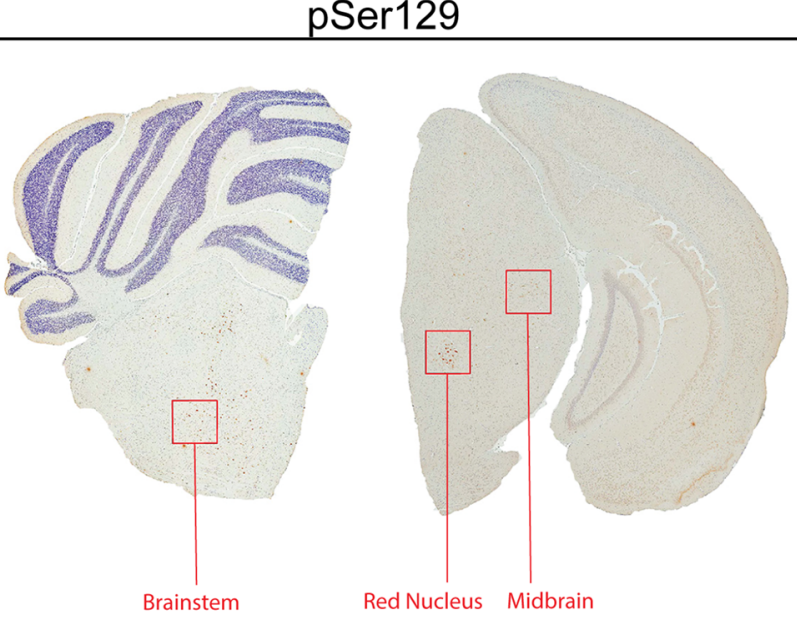

f

p62 sequestrome-1

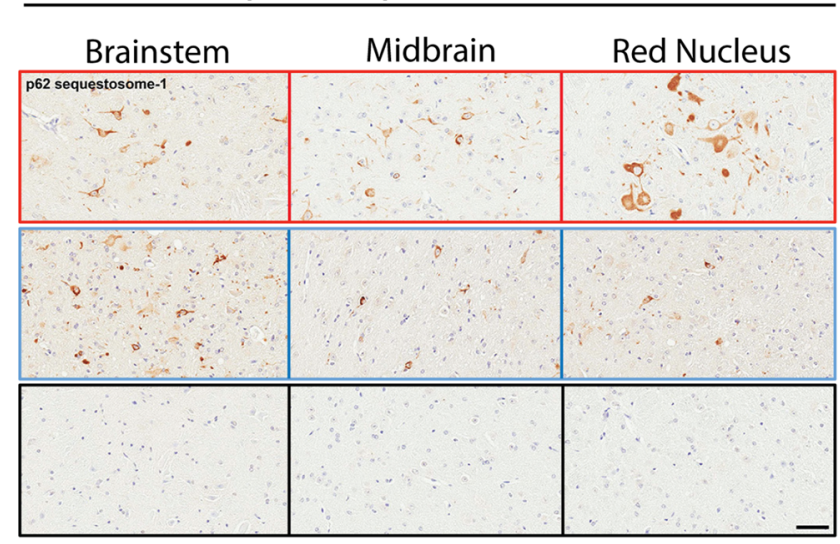

$\alpha$-Syn PFF mice in all brain regions analysed. Moreover, the 2H6 and 1D12 antibodies specifically stained intracellular inclusions that were more intense and larger in size in the $\alpha$-Syn/p25 $\alpha$ cohort, while they mostly detected pale reactive immunodots in the regular $\alpha$-Syn PFF mice. Interestingly,

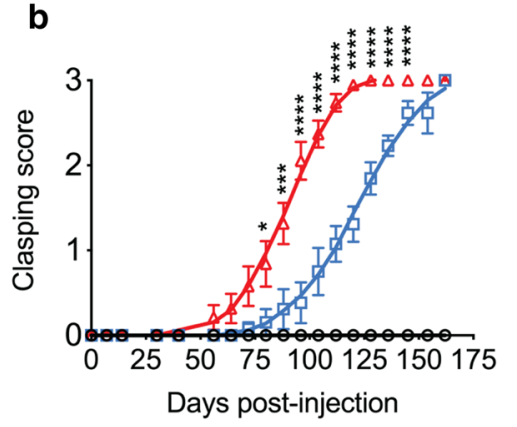

c

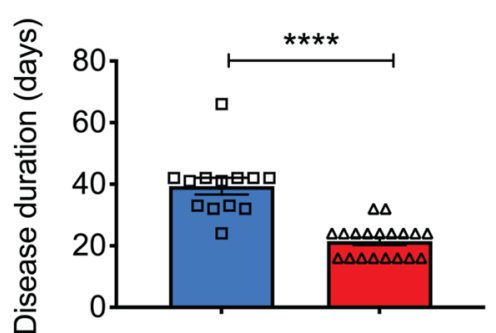

e

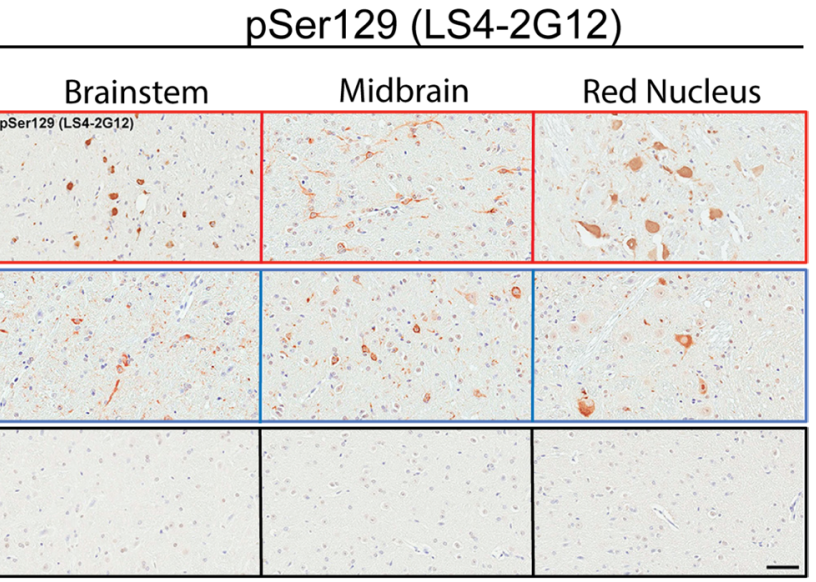

g

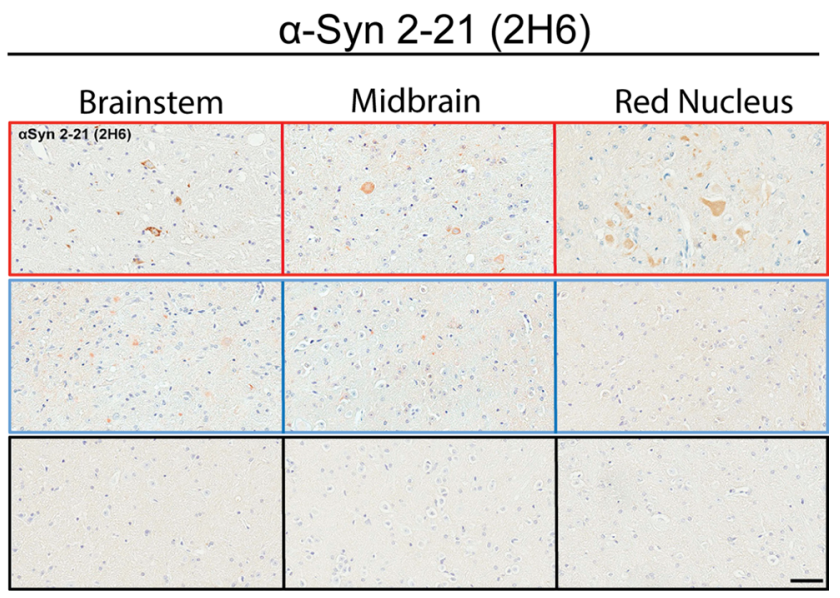

the cell bodies of neurons in the red nucleus seem to be particularly targeted by $\alpha-\operatorname{Syn} / \mathrm{p} 25 \alpha$ PFF, displaying increased $\alpha$-Syn epitope immunoreactivity for pSer129 (LS4-2G12 antibody in Fig. 4e; 81A and EP1536Y antibodies in Supplementary Fig. 5e, online resource), $\alpha$-Syn C-terminal 
4Fig. 4 Intramuscular injection of $\alpha-\operatorname{Syn} / \mathrm{p} 25 \alpha$ PFF induces earlier and more severe disease than $\alpha$-Syn PFF in a human A53T $\alpha$-Syn-transgenic mouse model. Human A53T $\alpha$-Syn-expressing M83 ${ }^{+/-}$mice were bilaterally injected with $\alpha-$ Syn or $\alpha-S y n / p 25 \alpha$ PFF $(10 \mu \mathrm{g} / \mathrm{leg})$ or PBS (vehicle control) into the hindlimb gastrocnemius muscle muscle. a Kaplan-Meier survival plot shows decreased survival time for age-matched M83 ${ }^{ \pm}$mice injected with $\alpha-\mathrm{Syn} / \mathrm{p} 25 \alpha$ PFF (red line, $n=19$ ) compared to $\alpha$-Syn PFF (blue line, $n=13$ ) and PBS (black line, $n=7$ ). $* * P<0.01$ as determined by log-rank (Mantel-Cox) test. b Hindlimb clasping was scored on a scale from 0 to 3 as a function of days after injection in the mice displayed in panel a and displayed as mean \pm s.e.m. The PBS-injected control mice did not develop clasping. Asterisks indicate $P<0.05$. *** $P<0.001$. $* * * * P<0.0001$ based on two-way ANOVA followed by Tukey's multiple comparisons test. c Duration of disease (from onset of clasping behaviour until death) for individual mice displayed in panel a injected with $\alpha$-Syn/p25 $\alpha$ PFF and $\alpha$-Syn PFF. PBS-injected control mice did not develop disease. Error bars indicate mean \pm SEM and $* * * * P<0.001$ as determined by one-way ANOVA test. d Lowmagnification coronal section of a $\alpha-S y n / p 25 \alpha$ PFF-injected mouse stained with a pSer129 $\alpha$-Syn-directed antibody LS4-2G12. Boxes indicate locations of brainstem, midbrain, and red nucleus regions analysed in age-matched M83 ${ }^{ \pm}$mice injected with $\alpha$-Syn/p25 $\alpha$ PFF $(n=7), \alpha$-Syn PFF $(n=7)$, and PBS $(n=7)$. Representative images are displayed of tissue immunohistochemically stained with antibodies reactive to: e pSer129 $\alpha$-Syn (LS4-2G12), f p62/sequestosome-1 staining as a marker of general inclusions, and $\mathbf{g} \mathrm{N}$-terminal of $\alpha$-Syn using the 2H6 monoclonal antibody against $\alpha$-Syn $2-21$. Scale bar $=50 \mu \mathrm{m}$ applies to panels $\mathrm{e}-\mathrm{g}$

(94-3A10 and 15-4A7 antibodies in Supplementary Fig. 5e, online resource), and $\alpha$-Syn N-terminal (Syn 506 antibody in Supplementary Fig. 5e, online resource). In addition, a higher number of ubiquitin (Supplementary Fig. 5e, online resource) and p62-positive (Fig. 4f) inclusions were found in the red nucleus of the $\alpha-\operatorname{Syn} / \mathrm{p} 25 \alpha$ cohort, indicating increased autophagic and/or proteasomal impairment and neurodegeneration. Quantitative analysis of pixel positivity for the N-terminal antibody $2 \mathrm{H} 6$ and the pSer129-directed 81a antibody demonstrated that there was no significant difference in the binding of the two antibodies to the total area of the red nucleus and the brain stem of mice inoculated with both strains (Supplementary Fig. 6, online resource) despite the evidently stronger staining of $\alpha$-Syn/p25 $\alpha$-challenged cell bodies (Fig. $4 \mathrm{e}-\mathrm{g}$ ). This suggests that the $\alpha-\operatorname{Syn} / \mathrm{p} 25 \alpha$ strain induces a stronger formation of inclusions in the cell bodies positive for the two antibodies, analogous to observations in human neurons (Fig. 3), whereas their antigens are more dispersed when induced by the $\alpha$-Syn strain.

To investigate the levels of $\alpha$-Syn aggregates in the affected tissue, we extracted frozen tissue corresponding to the pons and medulla oblongata (rich in $\alpha$-Syn pathology in the M83 model). The tissue homogenates were analysed using an FRET immune-based Cisbio platform. Figure 5a demonstrates the FRET signal obtained after $20 \mathrm{~h}$ of incubation using a 256 -fold dilution of the $10 \%$ brain homogenate. The $\alpha$-Syn/p25 $\alpha$-injected mice $(n=4)$ clearly stand out with a consistent and significantly larger signal than the
$\alpha$-Syn PFF $(n=4)$ and the PBS-control-injected mice $(n=3)$, demonstrating that they contain larger amounts of immunoreactive $\alpha$-Syn aggregates (Fig. 5a; Supplementary Fig. 7a, online resource). The $\alpha$-Syn PFF and the PBS control do not differ significantly, because of one $\alpha$-Syn PFF-injected outlier that showed very low signal (Supplementary Fig. 7d, online resource). Hence, the $\alpha-S y n / p 25 \alpha$ cohort that suffers a more severe disease phenotype and displays stronger cell body-associated $\alpha$-Syn pathology (Fig. 4e-g) harbours larger amounts of $\alpha$-Syn aggregates than the mice injected with the $\alpha$-Syn PFF (Fig. 5a; Supplementary Fig. 7a, online resource).

We next asked if the increased histopathology and biochemically detectable aggregate load correlate with an increased in vitro seeding activity that hypothetically could be responsible for the faster disease progression. To quantify the seeding activity of templating active $\alpha$-Syn aggregates, we used a PMCA technique. This technique can also generate substantial amounts of amplified $\alpha$-Syn aggregates, which allows subsequent biochemical analysis [92]. Using PMCA, we analysed the same pons/medulla region as used for the Cisbio FRET analysis. Figure $5 b$ demonstrates that a significant ThT signal developed after a lag phase of about $20 \mathrm{~h}$ when incubating recombinant HH-tagged- $\alpha$-Syn with $0.01 \%$ homogenates from sick end-stage $\alpha$-Syn $/ \mathrm{p} 25 \alpha(n=5)$ and the $\alpha$-Syn PFF $(n=3)$ injected mice. By contrast, no signal developed when using healthy controls of similar age $(n=3)$ injected with PBS. Analysis of individual mice revealed that all the end-stage mice injected with $\alpha$-Syn PFF $(n=3)$ displayed ThT signals that reached a similar plateau of around 10-15,000 AU (Supplementary Fig. 7b, online resource). This contrasted the $\alpha$-Syn/p25 $\alpha$ PFF-injected cohort, where two mice did not seed any aggregation, two generated signals of approximately 15-20,000 AU, and one mouse generated a signal around 1000 (Supplementary Fig. 7b, online resource). Strikingly, when diluting the tissue homogenates tenfold to $0.001 \%$ and $0.0001 \%$ prior to addition to the PMCA assay, the positive signals from the $\alpha$-Syn $/ \mathrm{p} 25 \alpha$-injected mice were lost. This contrast with the $\alpha$-Syn PFF-injected cohort where two mice remained positive at the highest dilution (Fig. 5c, d; Supplementary Fig. 7b-d, online resource). The data demonstrate variation within each small cohort, which was especially pronounced for the $\alpha$-Syn/p25 $\alpha$-injected mice. Proteinase K digestion of the parental generation 0 (G0) amplified aggregates demonstrated similar Syn-1 immuno-reactive band patterns in $\alpha$-Syn and $\alpha$-Syn $/ \mathrm{p} 25 \alpha$ cohorts, while a strong intragroup variation was observed in both cohorts (Fig. 5e). The band patterns did not allow the $\alpha$-Syn/p25 $\alpha$ and $\alpha$-Syn groups to be distinguished. The parental G0 samples contained both monomer HH- $\alpha$-Syn and diluted brain homogenate, so we reamplified the G0 samples in recombinant non-HH-tagged $\alpha$-Syn to G1 and G2 samples using 5\% insoluble aggregates 
FRET

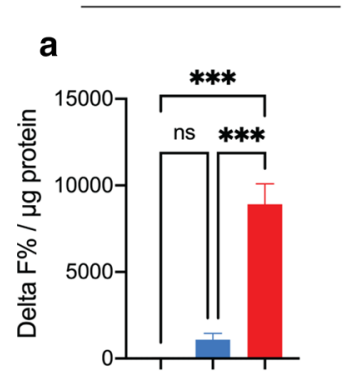

b

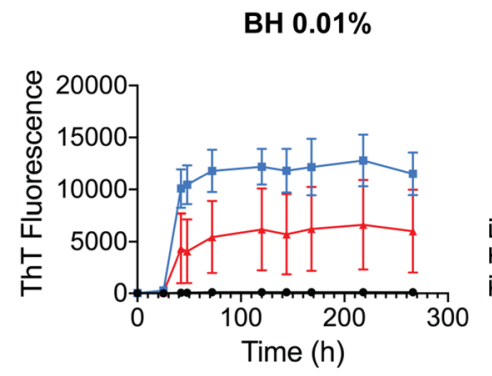

PMCA

c

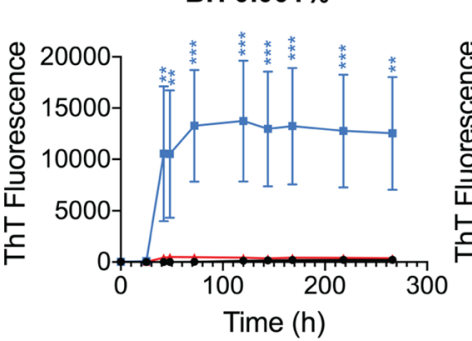

d

BH $0.0001 \%$ e

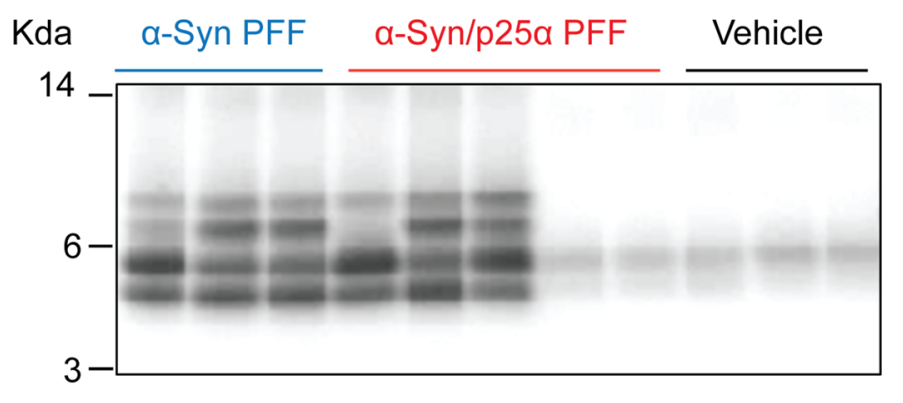

f

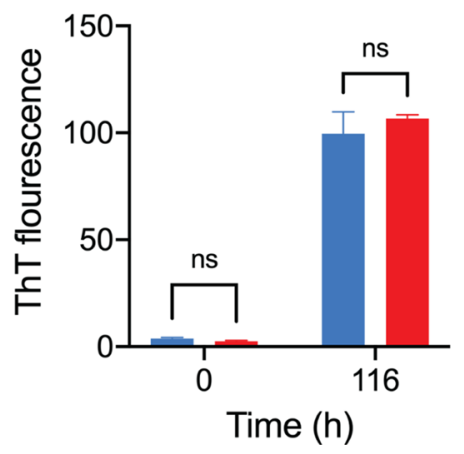

Fig. 5 Detection of $\alpha$-Syn aggregates in mouse brain samples by immuno- and PMCA assay and proteinase $\mathrm{K}$ digestion and thioflavin $\mathrm{T}$ analyses of amplified aggregates. a Brain homogenates of mice injected with $\alpha$-Syn/p25 $\alpha$ PFF contain more aggregated $\alpha$-Syn than mice injected with $\alpha$-Syn PFF. Aggregated $\alpha$-Syn was quantified in brain homogenates using an FRET immune-based Cisbio assay with three technical replicates per homogenate. The level of aggregated $\alpha$-Syn in the samples is expressed as delta F\%/ug protein. This represents the ratio of emission at $665 \mathrm{~nm} / 620 \mathrm{~nm}$ of the sample compared to the negative assay control normalized to the protein content (vehicle, $n=3$, mice \#19-21; $\alpha$-Syn PFF, $n=4$, mice \#3-6; $\alpha$-Syn/p25 $\alpha$ PFF $n=4$, mice mice \#12-15). Neuropathological information of mice samples is available in Supplementary Table 2, online resource. BCA protein measurements determined the total protein concentration of the homogenates. One-way ANOVA followed by Tukey's post hoc. Bars show mean \pm SEM $* * * \mathrm{P}<0.001$. b-d Brain homogenates of mice injected with $\alpha-\operatorname{Syn} / \mathrm{p} 25 \alpha$ PFF contain less templating active seeds than mice injected with $\alpha$-Syn PFF. Brain samples from mouse inoculated with $\alpha$-Syn PFF (blue line, $n=3$, mice \#1-3), $\alpha-S y n / \mathrm{p} 25 \mathrm{PFF}$ (red line, $n=5$, mice \#7-11), and vehicle (PBS, pH 7.4, black line, $n=3$, mice \#16-18) were homogenized at $10 \% \mathrm{w} / \mathrm{v}$.

as seeds. Using this approach, we were able to demonstrate that aggregates amplified from the two $\alpha$-Syn strain-injected groups were indistinguishable with respect to maximal ThT signals reached in the plateau phase (Fig. 5f). Hence, neither the activity of $\alpha$-Syn templating-competent seeds
Brain samples (at final concentrations of $0.01,0.001$ and $0.0001 \%$ ) were analysed in a 96-well plate $\alpha$-Syn-PMCA assay. The extent of aggregation was monitored by the increase in ThT fluorescence by a spectrofluorometer using an $\lambda_{\mathrm{ex}}=435 \mathrm{~nm}$ and an $\lambda_{\mathrm{em}}=485 \mathrm{~nm}$. Neuropathological information of mice samples is available in Supplementary Table 2, online resource. The experiments were carried out in duplicates, and error bars indicate mean \pm s.e.m. Asterisks indicate $* P<0.05$. $* * P<0.01$. $* * * P<0.001$ based on two-way ANOVA followed by Tukey's multiple comparisons test. e PMCA-amplified $\alpha$-Syn aggregates $(\mathrm{G} 0)$ were incubated with proteinase $\mathrm{K}(1 \mathrm{mg} / \mathrm{ml})$ at $37{ }^{\circ} \mathrm{C}$ for $2 \mathrm{~h}$. Proteins were separated on $12 \%$ Bis-Tris gel and immunoblotted with anti-alpha synuclein Syn-1 to visualise cleavage patterns. Molecular weight markers are indicated on the left in kiloDaltons (KDa). $\mathbf{f}$ G1 of PMCA-amplified $\alpha$-Syn aggregates were generated by seeding of $69 \mu \mathrm{M} \alpha$-Syn monomers with $3.5 \mu \mathrm{M}$ parental aggregated PMCA-amplified $\alpha$-Syn material (G0). ThT fluorescence was measured at beginning $(0 \mathrm{~h})$ and end-stage plateau $(116 \mathrm{~h})$ of the $\mathrm{G} 1$ re-amplification experiment. Bars represented as mean of signal from $\alpha$-Syn PFF-injected mice (blue, $n=3$ ) or $\alpha$-Syn/p25 $\alpha$ PFFinjected mice (red, $n=3$, \pm s.e.m analysed by two-way ANOVA followed by Sidak's multiple comparisons test. $n s$ not significant

in the tissue nor the PK-digestion pattern of the templated aggregates allowed us to distinguish between the two groups injected with different $\alpha$-Syn strains.

To determine if the two strains can induce different pathology and behavioural deficits in wild-type female 
C57BL/6 mice, we performed unilateral stereotaxic intracerebral injections (IC) of the two strains into the striata of wild-type mice and followed the animals at 1,3 , and 6 months after injection. As controls, we injected the mice with similar amounts of monomer $\alpha$-Syn. The mice were subjected to two behavioural tests, the challenging beam (Fig. 6a-e) and the cylinder test (Fig. 6f-i). In the challenging beam, the mouse has to traverse a beam with four frames that become progressively narrower and to finally enter its cage. At 3 months after injection, none of the cohorts showed any significant difference in motor behaviour in the challenging beam (Fig. 6b, c), while 6 months after injection, both groups of animals injected with $\alpha$-Syn aggregate strains exhibited hyperactivity compared to the controls as demonstrated by shorter time to cross and more steps per second (Fig. 6d, e). They were also quicker to transverse

\section{Challenging Beam}

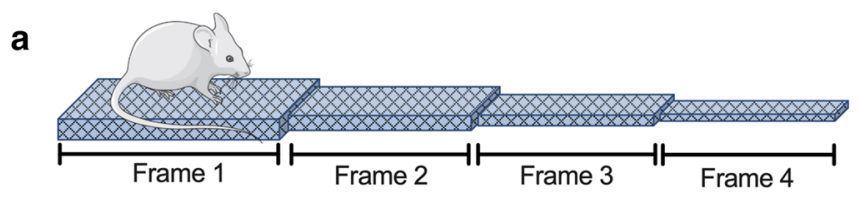

b
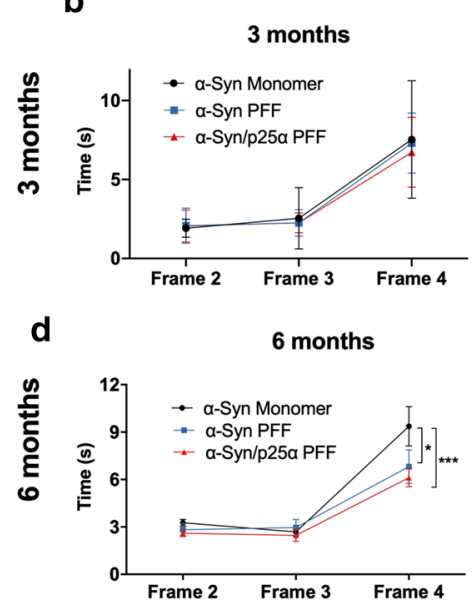

6 months

\section{Cylinder test}
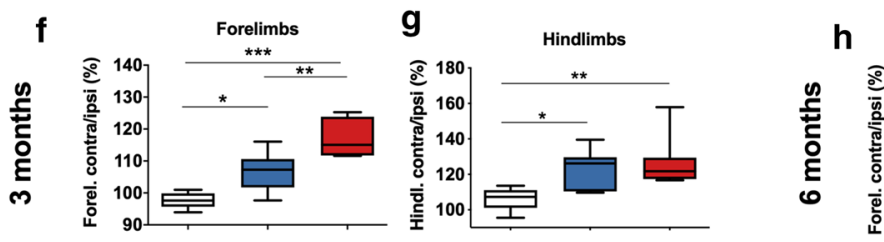

Fig. $6 \alpha$-Syn/p25 $\alpha$ PFF induces abnormal, progressive motor hyperactivity in wild-type mice. Wild-type mice were injected with $\alpha$-Syn or $\alpha$-Syn/p25 $\alpha$ PFF $(10 \mu \mathrm{g})$ or monomer $\alpha$-Syn $(10 \mu \mathrm{g})$ as negative control in their right striatum and were analysed for motor function by the challenging beam and cylinder test at 3 and 6 months after injection. a The challenging beam test measures the time spent, steps taken, and errors in crossing a progressively thinner beam and to enter a cage after the last frame 4 . b-c No significant changes were observed between the three groups at 3 months after injection ( $\alpha$-Syn monomeric, $n=15 ; \alpha$-Syn PFF, $n=16 ; \alpha$-Syn/p25 $\alpha$ PFF, $n=16$ ), d 6 months after injection, both $\alpha$-Syn PFF and $\alpha-S y n / p 25 \alpha$ PFF-injected animals transversed frame 4 faster than $\alpha$-Syn monomeric animals ( $\alpha$-Syn monomeric, $n=9 ; \alpha$-Syn PFF, $n=10$; $\alpha$-Syn/ p25 $\alpha$ PFF, $n=10$ ). Two-way ANOVA followed by Tukey's post hoc. Error bars indicate mean \pm SEM. $* P<0.05$. $* * * P<0.001$. e The faster crossing of frame 4 for both groups was due to more steps/s
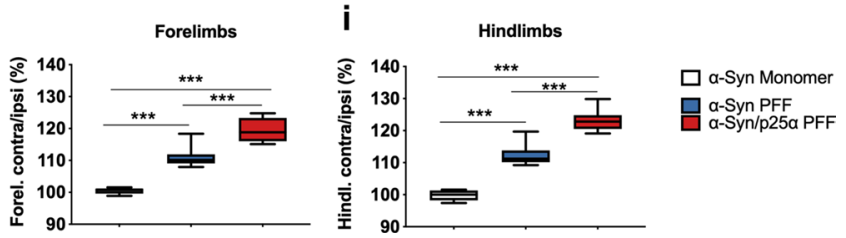

Frame 4

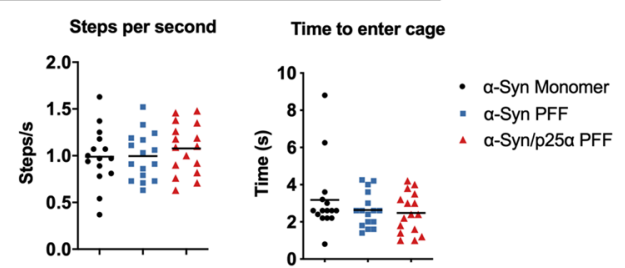

than the $\alpha$-Syn monomeric animals and they also used less time to enter the home cage. One-way ANOVA followed by Tukey's post hoc. Error bars indicate mean \pm SEM. $* P<0.05$. $* * P<0.01$. The cylinder test revealed an early and persistent side-bias hyperactivity of PFF-injected animals that at 3 month $\mathbf{f}-\mathbf{g}$ where animals injected with both PFF polymorphs used the contralateral limbs more than $\alpha$-Syn monomeric-injected mice, and with the $\alpha$-Syn/p25 $\alpha$ PFF even more strongly affecting the forelimb than in the $\alpha$-Syn PFF mice ( $\alpha$-Syn monomeric, $n=6$; $\alpha$-Syn PFF, $n=8$; $\alpha$-Syn/p25 $\alpha$ PFF, $n=8$ ). One-way ANOVA followed by Tukey's post hoc. Error bars indicate mean \pm s.e.m. $* P<0.05$. $* * P<0.01$. $* * * P<0.001$. h, i This difference between the $\alpha$-Syn PFF and the $\alpha-\operatorname{Syn} / \mathrm{p} 25 \alpha$ PFF mice became more obvious at 6 months after injection, where there also was a difference in hindlimb use. ( $\alpha$-Syn monomeric, $n=9 ; \alpha$-Syn PFF, $n=10$; $\alpha$-Syn/p25 $\alpha$ PFF, $n=10$ ). One-way ANOVA followed by Tukey's post hoc. Bars show min and max. $* * * P<0.001$ 
a-Syn Monomer $\square$ a-Syn PFF $\square$ a-Syn/p25a PFF

a

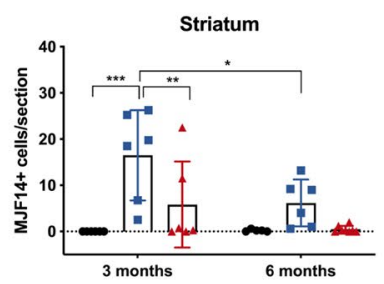

b

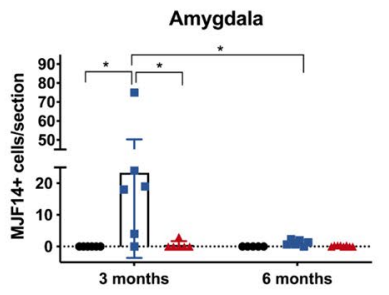

C

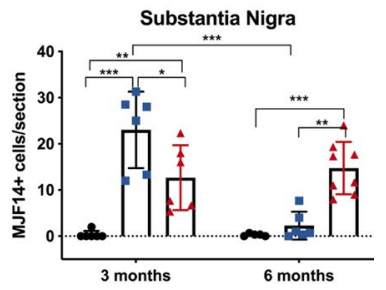

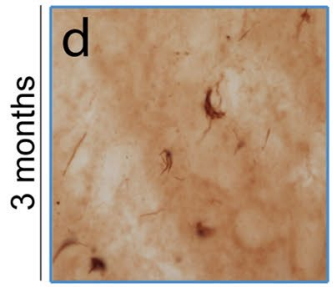

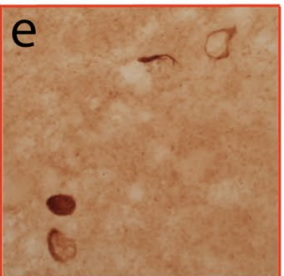

h

Substantia Nigra

Dopaminergic Neurons
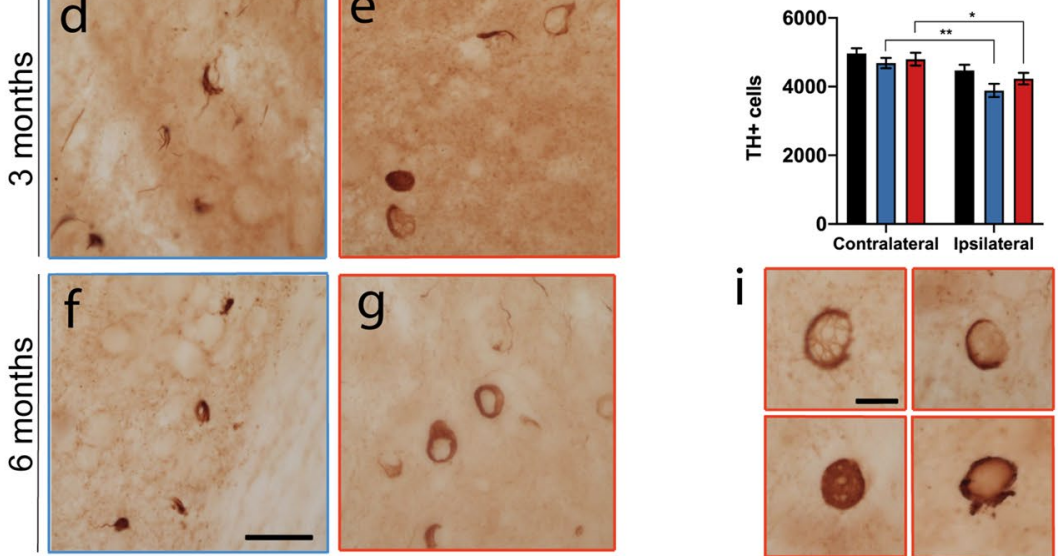

MJF14 - 6 months

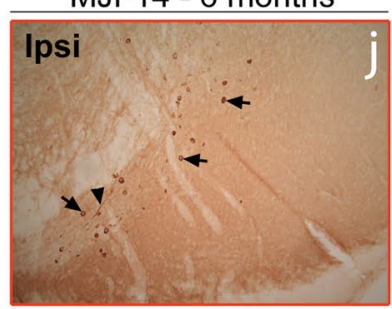

Tyrosine Hydroxylase - 6 months
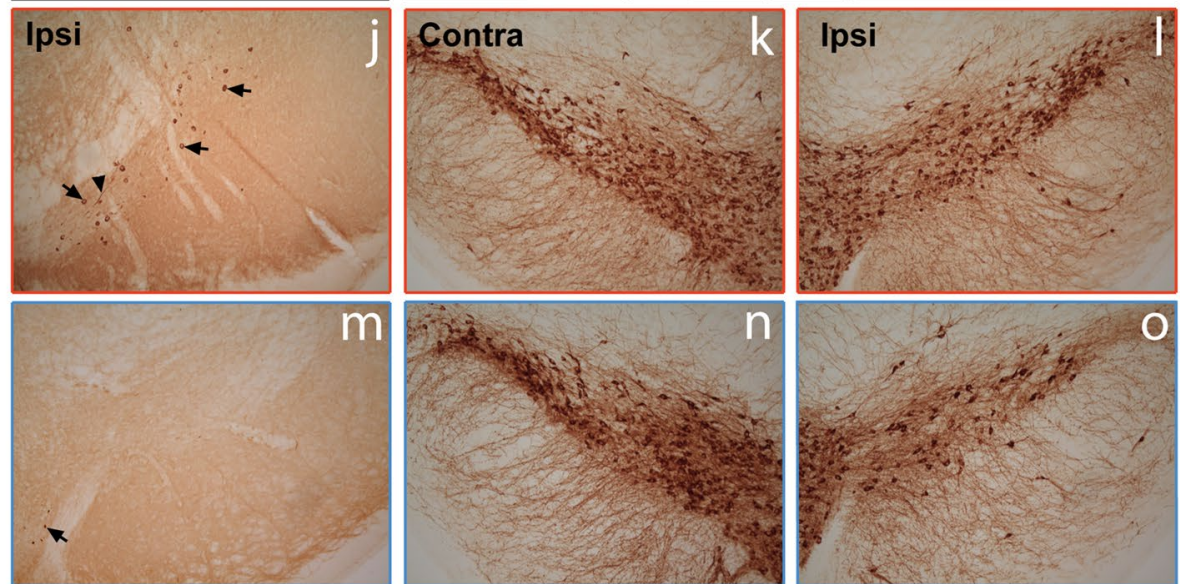

(1)
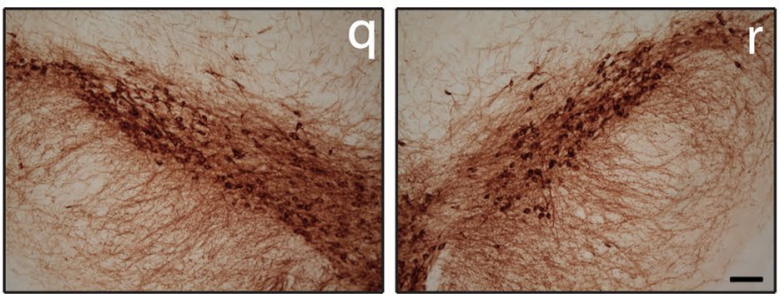
४Fig. $7 \alpha$-Syn/p25 $\alpha$ PFF induces preferential $\alpha$-Syn aggregation in nigro-striatal neurons. Progression of the $\alpha$-Syn pathology and dopaminergic neurodegeneration in mice injected with $\alpha$-Syn monomer, $\alpha$-Syn PFF or $\alpha$-Syn/p25 $\alpha$ PFF was assessed by immunohistochemistry and stereology. a-c Brain sections were immunostained with an antibody against aggregated $\alpha$-Syn (MJF-14); the labelled cell body structures were counted in striatum, amygdala, and substantia nigra $(\mathrm{SN})$, and the average number of cells per coronal section in each group was calculated at 3 and 6 months after injection. d-g Representative images of cellular structures immunostained with MJF-14 antibody in the SN. Notice that MJF-14-labelled structures observed in the ventral midbrain cells of $\alpha$-Syn PFF-injected animals extended into neurites and preferentially were segregated into parts of the perinuclear space $(\mathbf{d}, \mathbf{f})$; that contrasts with the circular perinuclear staining found in the mice injected with $\alpha$-Syn/p25 $\alpha$ PFF $(\mathbf{e}, \mathbf{g})$. h Stereological quantification of tyrosine hydroxylase (TH)-positive cells in SN showed a significant decrease of neurons in the ipsilateral side of the $\alpha$-Syn PFF-injected group and in the $\alpha$-Syn $/ \mathrm{p} 25 \alpha$ PFF-injected group, while no changes were found after monomeric $\alpha$-Syn injections. In $\mathbf{i}$, details of the different cells found in $\mathrm{SN}$ of the $\alpha-$ Syn/p25 $\alpha$ PFF animals at 6 months are presented. j, m, p Representative images of SN immunostained with MJF-14 antibody in all three groups at 6 months. Notice that MJF- $14^{+}$structures observed in the $\alpha$-Syn PFF-injected animals were normally located in the ventral medial midbrain in the border with VTA $(\mathbf{m})$, while cells (arrows in j) and fibres (arrowhead in $\mathbf{j}$ ) were located in the SN compacta in the $\alpha-$ Syn/p25 $\alpha$ PFF animals. $\mathbf{k}, \mathbf{l}, \mathbf{n}, \mathbf{o}, \mathbf{q}, \mathbf{r}$ Representative images of the contralateral $\mathrm{SN}$ and its correspondent ipsilateral side from sections immunostained with TH antibody in all three groups at 6 months. Notice the decrease in the number of cell bodies in the ipsilateral side of the $\alpha$-Syn PFF-injected mice in $\mathbf{o}$ and the $\alpha$-Syn/p25 $\alpha$ PFF-injected mice in (l). Data are average \pm SD. $\mathbf{a}-\mathbf{c}$ or SEM. $\mathbf{h}$ Two-way ANOVA followed by Sidak post hoc. ${ }^{*} P<0.05$. ** $P<0.01$. *** $P<0.001$. Scale in $f=25 \mu \mathrm{m}$ applies to $\mathbf{d}-\mathbf{g}$, scale in $i=10 \mu \mathrm{m}$ and applies to insets and scale in t: $100 \mu \mathrm{m}$ applies to $(\mathbf{j}-\mathbf{r})$

the last frame and enter the home cage (Fig. 6c, e). In the cylinder test, the use of fore- and hindlimbs was quantified to determine the presence of asymmetry in the use of limbs. As early at 3 months after injection, the mice injected with aggregated $\alpha$-Syn strains developed asymmetry and used the contralateral fore- and hindlimbs more that the controls (Fig. 6f, g). The motor asymmetry of the forelimbs was significantly higher in the $\alpha-\operatorname{Syn} / \mathrm{p} 25 \alpha$ cohort than in the $\alpha$-Syn PFF mice (Fig. 6f), and it became also apparent in the hindlimbs at 6 months after injection (Fig. 6i). Thus, injection of aggregated $\alpha$-Syn resulted in a progressive and asymmetric motor hyperactivity that was more-pronounced in the $\alpha-\operatorname{Syn} / \mathrm{p} 25 \alpha$ cohort.

Immunohistochemical analysis of the brains showed no obvious $\alpha$-Syn pathology 1 month after injection of the PFF, as assessed by the MJF-14 antibody (not shown). However, at 3 months, both groups injected with aggregated $\alpha$-Syn strains showed MJF14 ${ }^{+}$structures in the area of injection (striatum) and connected anatomical regions, while mice injected with monomeric $\alpha$-Syn showed no apparent positive MJF14 staining (Fig. 7a-c; Supplementary Fig. 8, online resource). Especially animals receiving $\alpha-S y n$ PFF showed obvious pathological $\alpha$-Syn accumulations in cortex, piriform cortex, amygdala, and SN (Supplementary Fig, 8, online resource). By contrast, the $\mathrm{MJF} 14^{+}$structures in the $\alpha-\operatorname{Syn} / \mathrm{p} 25 \alpha$ cohort were mostly confined to the striatum and SN, with significantly fewer cellular structures than in $\alpha$-Syn PFF mice (Fig. 7a-c; Supplementary Fig. 8, online resource). This suggests that the $\alpha-$ Syn PFF strain had an ability to induce progressive histopathology in neurons of multiple brain areas similar to that of the $\alpha-S y n / p 25 \alpha$ PFF that exhibited a "tropism" for nigro-striatal neurons. The number of MJF14 ${ }^{+}$cell bodies decreased significantly after 3 months in all areas in the $\alpha$-Syn PFF mice (Fig. 7a-c). However, in the $\alpha-S y n / p 25 \alpha$ cohort, the number of MJF14 ${ }^{+}$ cells in $\mathrm{SN}$ remained elevated and, at this point, was significantly higher than in the $\alpha$-Syn PFF animals (Fig. 7c). The $\alpha$-Syn PFF-induced MJF14 ${ }^{+}$skein-like structures in the neurons were detectable from 3 month and onward (Fig. 7d, f). Already at 3 months, the $\alpha$-Syn/p25 $\alpha$ strain induced perinuclear ring-like and half-moon-shaped inclusions and even dense staining that covered the entire cell body (Fig. 7e). At 6 months, most of the MFJ14+ inclusions appeared perinuclear and were preferentially accumulated in the SN pars compacta but not in striatum (Fig. $7 \mathrm{~g}, \mathrm{j}$ ). By contrast, the MJF14 ${ }^{+}$cells in the midbrain of the $\alpha$-Syn PFFinjected mice were fewer, more granular, and seemed more constrained to the border with the ventral tegmental area while still prominent in striatum (Fig. 7a, f, m). Stereological analysis of the tyrosine hydroxylase $\left(\mathrm{TH}^{+}\right)$dopaminergic neurons in $\mathrm{SN}$ showed a significant decrease of $\mathrm{TH}^{+}$nigral neurons in the ipsilateral side of the midbrain (Fig. 7h), of the $\alpha$-Syn PFF (Fig. 7n, o) and the $\alpha$-Syn/p25 $\alpha$ PFF mice (Fig. 7k, 1). Interestingly, at 6 months after $\alpha-S y n / p 25 \alpha$ PFF inoculation, the percentage of surviving $\mathrm{TH}^{+}$cells (as compared to contralateral $\mathrm{TH}^{+}$cells) was negatively correlated with the number of MJF14 ${ }^{+}$cells in $\mathrm{SN}$; therefore, animals with a higher number of cells containing aggregated $\alpha$-Syn showed more dopaminergic loss, while such a correlation was not found in the $\alpha$-Syn PFF group (Supplementary Fig. 9b, online resource).

Interestingly, we observed that the brains' inflammatory response was significantly lower in the $\alpha-S y n / p 25 \alpha$ PFF mice than in the other groups, including monomeric $\alpha$-Syn (Supplementary Fig. 10, 11, online resource). This was true when both astrocyte and microglia response were analysed. GFAP upregulation was observed in the ipsilateral striatum 1 month after injection of $\alpha$-Syn. This upregulation was highest in $\alpha$-Syn PFF, followed by monomeric animals with the $\alpha$-Syn/p25 $\alpha$ PFF-injected animals showing the lowest upregulation (Supplementary Fig. 10, online resource). This astrocytic response was decreased after 6 months in all three groups, at a point where the contralateral striatum showed more $\mathrm{GFAP}^{+}$than at 1 month, suggesting a bi-lateralization of the glia response (Supplementary Fig. 10, online resource). Microgliosis, as 
revealed by Iba1 immunostaining, was observed in the ipsilateral striatum after 1 month in all three groups; but again, the highest changes in Iba ${ }^{+}$cell number and morphology were found in the $\alpha$-Syn PFF group, while the $\alpha$-Syn/p25 $\alpha$ PFF animals showed the lowest number and morphology (Supplementary Fig. 11, online resource). Confirming the lower neuroinflammatory activation in the $\alpha$-Syn $/ \mathrm{p} 25 \alpha$ animals, while MHCII expression in the ipsilateral striatum was upregulated in all three groups, the neuroinflammatory activation was significantly higher in the $\alpha$-Syn PFF animals than in the other two groups, with the $\alpha$-Syn/p25 $\alpha$ PFF showing a very scarce MHCII expression (Supplementary Fig. 12a, c-e, online resource). These striatal MHCII-ramified cells disappeared after 3 months in all three groups (Supplementary Fig. 12a, online resource), and no significant MHCII expression was found at 6 months (not shown). Ipsilateral Iba $1^{+}$microgliosis appeared lower after 6 months, but $\alpha$-Syn PFF animals showed cells with higher Iba1 expression and numerous ramifications, while this was not observed in $\alpha-\operatorname{Syn} / \mathrm{p} 25 \alpha$

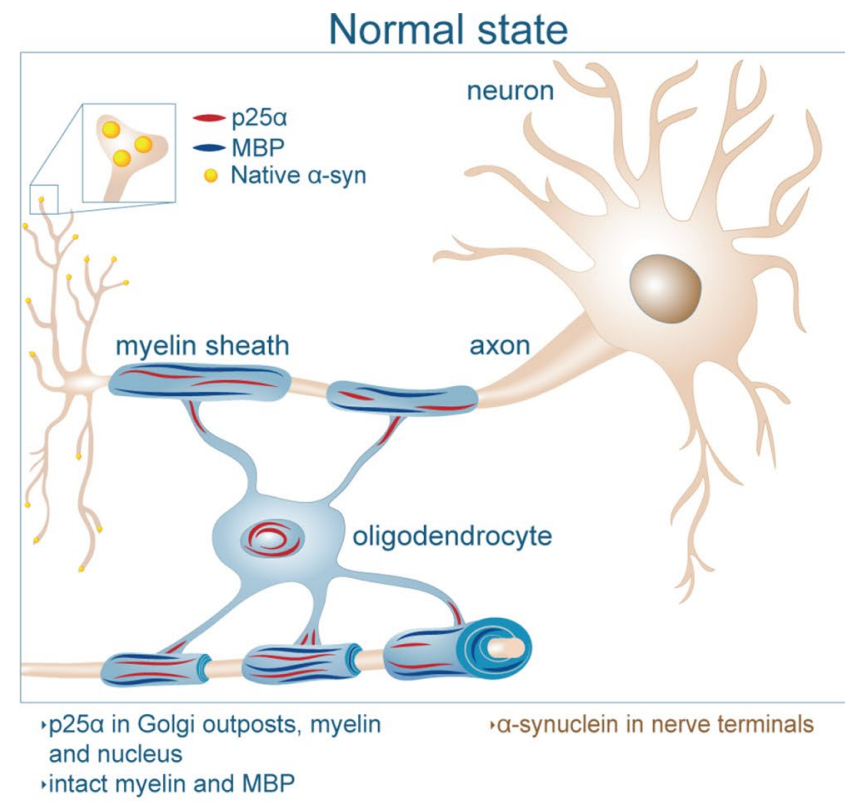

Fig. 8 Hypothetical mechanism for the generation of an MSA-associated $\alpha$-Syn strain with increased neurotoxicity induced by oligodendroglial protein p25 $\alpha$ TPPP. Left panel: p25 $\alpha /$ TPPP is expressed in mature oligodendrocytes and is vital for reorganisation and stabilisation myelin. In the physiological state, p25 $\alpha$ /TPPP can be found in Golgi outposts in myelin outside the cell body and in the nucleus. The myelin basic protein (MBP) is present in intact myelin. Right panel: In MSA, the oligodendroglial cell body expands, and MBP is degraded leading to demyelination. p25 $\alpha$ /TPPP retracts from myelin and exits the nucleus forming early cytoplasmic inclusions. Low
PFF mice. The bi-lateralization of the neuroinflammatory response also appeared true for microglia. In the SN, GFAP or Iba-1 expression did not appear different among sides and groups at 1 month (not shown) or at 6 months (Supplementary Fig. 10 and 11, online resource). However, we observed a general bilateral upregulation of the phagocytic marker CD68 in the SN (which normally is expressed at very low levels in the mouse brain) in both monomeric and $\alpha$-Syn PFF mice. However, we found a significantly lower CD68 expression in the $\alpha$-Syn/p25 $\alpha$ cohort (Supplementary Fig. 12b,fh, online resource), which is in accordance with the lower neuroinflammatory response in this group.

In conclusion, compared to the control $\alpha$-Syn PFF, $\alpha$-Syn/ p25 $\alpha$ PFF induce a faster onset and more aggressive disease phenotype in the human A53T $\alpha$-Syn-transgenic mouse model. In wild-type mice, striatal inoculation of $\alpha-\operatorname{Syn} / \mathrm{p} 25 \alpha$ PFF elicited a certain "tropism" for nigro-striatal neurons, where it induced a greater motoric deficit in the cylinder test and a distinctive long-lasting $\alpha$-Syn pathology correlating

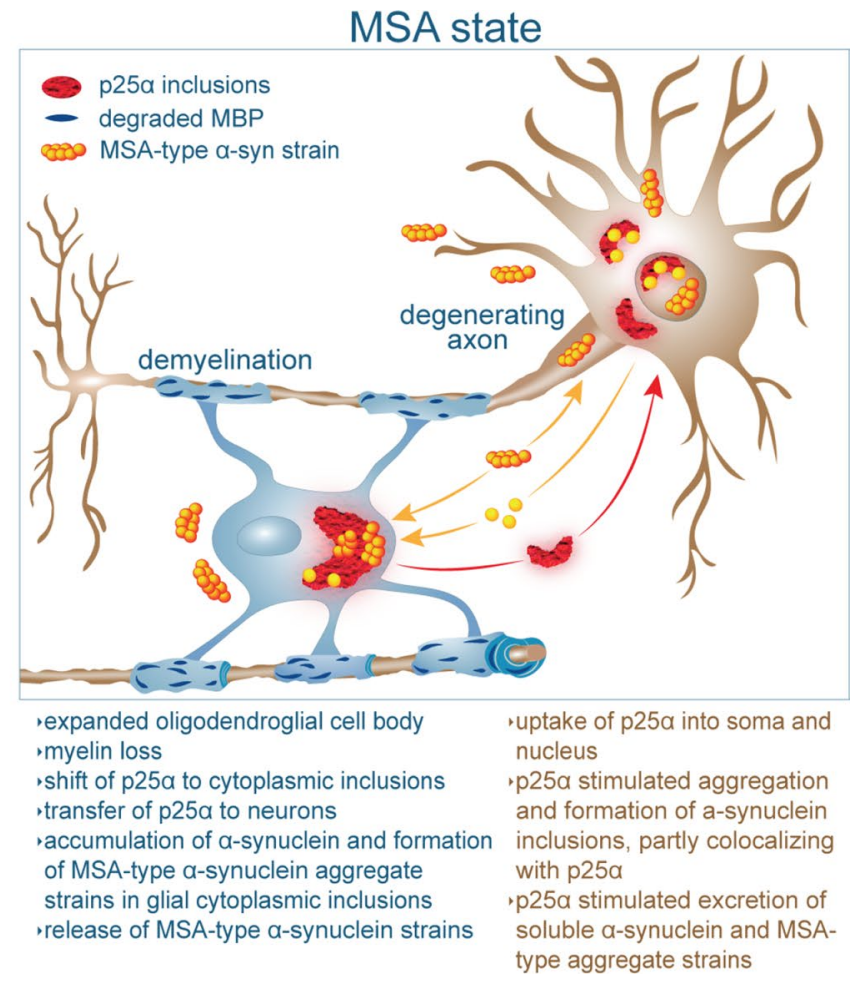

levels of $\alpha$-Syn monomers are then recruited to the inclusion where P25 $\alpha /$ TPPP nucleate them into MSA-type $\alpha$-Syn aggregate strains completing the formation of mature glial cytoplasmic inclusions. P25 $\alpha$ /TPPP is released from oligodendrocytes and taken into neurons where it exists in nuclear and extranuclear inclusions in the absence and presence of $\alpha$-Syn and induce formation of MSA-type $\alpha$-Syn polymorphs that accumulate in neurites and nuclei as neuronal nuclear and cytoplasmic inclusions causing neuronal degeneration. The P25 $\alpha /$ TPPP facilitates the spreading of the disease process by stimulating atypical secretion of $\alpha$-Syn aggregates 
with neuron death; and this occurred on the background of a reduced neuroinflammatory response compared not only to the $\alpha$-Syn PFF but also to monomeric $\alpha$-Syn.

\section{Discussion}

Although the three synucleinopathies PD, DLB, and MSA share the progressive development of $\alpha$-Syn aggregate-containing cytoplasmic inclusions, the histopathology in MSA exhibits a range of special characteristics. The most recognised feature is that the burden of $\alpha$-Syn inclusion pathology is larger in MSA than in PD and DLB, and the cytoplasmic inclusions predominantly reside in oligodendrocytes $[17,36$, 66]. Such oligodendroglial cytoplasmic inclusions also exist, although less abundantly, in PD and DLB associated with familiar $\alpha$-Syn mutations and in the pallidothalamic tract in sporadic DLB [45, 75]. However, in MSA, $\alpha$-Syn aggregates also frequently occur in neurons as neuropil threads and in neuronal nuclear and cytoplasmic inclusions $[36,66]$. The significant neuronal loss in MSA-affected regions might result in underestimation of the prevalence of $\alpha$-Syn neuronal inclusion that occurred in the tissue [36, 112]. At the molecular level, the $\alpha$-Syn molecules in GCI are organised differently from those in LB as demonstrated by different presentation of $\alpha$-Syn epitopes [19,65]. These observations were corroborated by the high-resolution structure of two unique $\alpha$-Syn polymorphs isolated from MSA brains that differed from those isolated from DLB brains [89]. In addition, $\alpha$-Syn aggregates amplified from CSF samples of MSA patients with the PMCA technique display a lower ThT fluorescence than aggregates amplified from PD patients [92], which is a characteristic shared with our p25 $\alpha$-induced PFF polymorph. Functionally, $\alpha$-Syn aggregate seeds from MSA brain extracts induce a very aggressive disease phenotype compared to PD when injected into brains of the human A53T- $\alpha-$ Syn-transgenic M83 mouse line [79, 108]. This enhanced toxicity is likely mediated by intrinsic structural characteristics, as it can be recapitulated in cells and rodents upon inoculation of PFF generated in vitro via PMCA of $\alpha$-Syn seeds isolated from MSA brain extracts [54, 106].

The molecular mechanisms causing $\alpha$-Syn to aggregate into functionally more aggressive polymorphs in MSA remain a conundrum, but the intracellular oligodendroglial milieu has been hypothesised to be responsible for forming these strains [77].

We hypothesised that the oligodendroglial protein $\mathrm{p} 25 \alpha$ is a causative factor that contributes to both the oligodendroglial milieu but also facilitates direct prodegenerative actions in neurons and between neurons and oligodendrocytes (Fig. 8).

Within oligodendrocytes in MSA, p25 $\alpha$ redistributes from its normal positions in myelin and the nucleus to accumulate in $\alpha$-Syn-negative perinuclear inclusions that may represent immature GCI [94]. Here, $\alpha$-Syn gradually appears and transforms them into mature GCI $[48,58,94]$ in a process that parallels the MSA-dependent expansion of the oligodendroglial cell body [74, 83]. The interaction between $\alpha$-Syn and p25 $\alpha$ stimulates $\alpha$-Syn aggregation [58] and $\alpha$-Syn aggregate-dependent dysfunctions in $\mathrm{p} 25 \alpha$-expressing cells including oligodendrocytes (Fig. 8) [21, 51, 65]. P25 $\alpha$ may even represent the unknown factor in myelin-rich white matter extracts of $\alpha$-Syn knockout mice that triggered $\alpha$-Syn aggregate pathology when injected into the human A53T$\alpha$-Syn-transgenic M83 line [85]. The presence of $\alpha$-Syn in the MSA oligodendrocytes has been the subject of several investigations, because $\alpha$-Syn is not considered an oligodendroglial protein [71]. However, a recent qPCR analysis of oligodendrocytes isolated from human brain demonstrated $\alpha$-Syn mRNA in oligodendrocytes [4]. Moreover, oligodendroglial cell lines and in vitro cultured human and rodent oligodendroglial cells express $\alpha$-Syn mRNA and protein $[18,32,65]$ that upon aggregation, e.g., triggered by $\mathrm{p} 25 \alpha$ or templated by exogenous $\alpha$-Syn seeds, increases the low level of endogenous $\alpha$-Syn by forming stable $\alpha$-Syn aggregates $[44,44,65]$. Such aggregation of endogenous $\alpha$-Syn in oligodendrocyte precursor cells, which remain in the cell through the further differentiation into oligodendrocytes, has been hypothesised to represent a mechanism for the prodegenerative activity of $\alpha$-Syn in MSA [43]. Moreover, it may be involved in the oligodendroglial down-regulation of myelin genes, neuronal upregulation of synapse genes, and glial inflammatory response observed in MSA-C tissue [78].

$\mathrm{P} 25 \alpha$ also has direct roles in neurons affected by neurodegenerative diseases, because it is present in pretangle-bearing neurons of Alzheimer's disease [48] and co-exist with $\alpha$-Syn in LB in PD and DLB. In MSA, p25 $\alpha$ was detected in $40 \%$ of neuronal cytoplasmic $\alpha$-Syn inclusions and in $10 \%$ of neuronal nuclear $\alpha$-Syn inclusions and also occurred in inclusions without $\alpha$-Syn [6]. Hence, while p25 $\alpha$ expression in neurons under physiological conditions is considered low, in individual neurons in MSA, it exists in significant levels that may initiate aggregation of $\alpha$-Syn into aggressive strains. P25 $\alpha$ also stimulates unconventional secretion of $\alpha$-Syn aggregates from neurons by blocking autophagic pathways [21]. This can contribute to non-cell autonomous functions by activation of microglia and astrocytes [98] and transport of templating active $\alpha$-Syn polymorphs into neighbouring oligodendrocytes and neurons. This could form the basis for the strong neuroinflammation and neuronal loss in MSA.

Our p $25 \alpha$-induced $\alpha$-Syn strain differed from the $\alpha$-Syn control strain on several biochemical parameters that have been demonstrated to vary between strains amplified from MSA and PD $[92,106]$. This ranged from differential binding of the fluorescent amyloid dye thioflavin $\mathrm{T}$ and the 
aggregate-specific FILA-1 antibody [106] to subtle changes in secondary structure (CD and FTIR) and altered proteolytic peptide patterns as demonstrated by Coomassie Blue staining and immunoblotting with Syn-1 and LB509 antibodies [77, 92, 106].

Higher resolution analysis of the $\alpha-\operatorname{Syn} / \mathrm{p} 25 \alpha$ strain by solid-state NMR spectroscopy allowed us to demonstrate that the $\alpha$-Syn $/ \mathrm{p} 25 \alpha$ strain exhibits a novel structure which, based on Ile88, resembled the reported fibril more than the ribbon structure $[28,29]$. Our results indicate that induction of $\alpha$-Syn aggregation by a brain protein or brain extract holds promise for generating more pathophysiological $\alpha$-Syn polymorphs than those induced by simply changing buffer conditions [102].

We used substoichiometric concentrations of p $25 \alpha$ to induce the formation of the $\alpha$-Syn/p25 $\alpha$ polymorph, because our aim was to demonstrate that this oligodendroglial factor, which likely occurs in low amount in neurons, holds potential for inducing a novel $\alpha$-Syn strain. We validated the specificity of the p25 $\alpha$-induced $\alpha$-Syn aggregation by showing that control proteins, such as BSA and carbonic anhydrase, neither enhanced aggregation nor induced formation of a novel folding, as determined by fluorometry. The $\alpha$-Syn $/ \mathrm{p} 25 \alpha$ strain can be sustainedly seeded and templated over multiple generations in vitro, using pure preparations of $\alpha$-Syn monomers, in the absence of $\mathrm{p} 25 \alpha$. This assures that their functional properties do not rely on any p $25 \alpha \mathrm{mol}-$ ecules associated with the fibrils, but rely on the actual folding of the fibrils. In this paradigm, p25 $\alpha$ acts at the level of building the seed, but is not as such an inherent part of the final $\alpha$-Syn strain. The initial induction of $\alpha$-Syn aggregation by p25 $\alpha$ may occur in both neurons and oligodendrocytes, because the two proteins co-exist in both cell types in MSA $[48,58,83,94]$.

This supports the wider hypothesis that other brain proteins than p25 $\alpha$, e.g., tau, and metabolic and gut-derived factors $[5,30,87,88]$ sculpt the folding of $\alpha$-Syn polymorphs, while the disease is progressively spreading through different cellular populations. This would suggest that a Braak stage 2 PD patient may be affected by strains induced by gut-associated factors, but can change strains in Braak stage 4 where the milieu of the dopaminergic neurons can affect $\alpha$-Syn aggregates in the nigro-striatal pathway $[64,91]$, which might in turn differ from those affecting the neocortex in Braak stage 5-6.

A trivial non-structure-based factor that can confound seeding-based cell and in vivo experiments is whether the number of seeds differs significantly between preparations of strains [1]. The two preparations used in this study were sonicated prior to usage and validated both by determination of protein concentration and of size distribution of particles by DLS. We observed that the $\alpha-\operatorname{Syn} / \mathrm{p} 25 \alpha$ strain consistently yielded larger particles than the $\alpha$-Syn control strain.
We ascribe this to either a larger flexibility or larger stability of the $\alpha-S y n / p 25 \alpha$ aggregates, which renders them less prone to breakage when subjected to ultrasound. This should result in a lower number of particles when using equal amounts of filaments as starting material. Despite a potentially lower particle number, we consistently observed stronger effects of the $\alpha$-Syn/p25 $\alpha$ polymorph across cell and animal models, which corroborates the existence of truly structure-dependent effects.

In cell models, the $\alpha$-Syn/p25 $\alpha$ strain templated larger inclusions when added to $\alpha$-Syn-expressing cells ranging from mitotic oligodendroglial OLN-AS7 cells to human neuronal stem cell-derived neurons. The effect was likely caused by their intracellular templating activity, because both strains were equally well taken up by OLN cell. Rather, it reflects a different proteostatic handling of the intracellular aggregates being templated by the two polymorphs. This resembles the $\alpha$-Syn-polymorph-specific inclusions seeded in iPSC-derived human cortical neurons [34] and in HEK293T cells expressing $\alpha$-Syn fused to fluorescent reporter proteins [116].

To compare the functional effects of the $\alpha-\operatorname{Syn} / \mathrm{p} 25 \alpha$ and the $\alpha$-Syn control strains in vivo, we used both the hA53Ttransgenic M83 line and wild-type C57BL/6 mice, and observed that the $\alpha-S y n / p 25 \alpha$ strain induced differential $\alpha$-Syn inclusion pathology, motor phenotypes, and timeto-death in the models. Inoculation of heterozygous M83 mice with the $\alpha-S y n / p 25 \alpha$ strain decreased the disease-free period and induced a more aggressive disease phenotype as defined by a $45 \%$ shorter time from first symptom to death. This resembles the more aggressive disease observed when injecting PFF amplified from MSA brain [54]. The $\alpha-S y n /$ p25 $\alpha$ strain induced more prominent pathology revealed by pS129 and p62 sequestrome-1 immunoreactivity reminiscent of MSA compared to PD [55]. The inclusions induced by the $\alpha-\operatorname{Syn} / \mathrm{p} 25 \alpha$ strain displayed a differential binding of especially $\mathrm{N}$-terminally directed $\alpha$-Syn antibodies, which suggests a different structure of the aggregates formed by the two strains. The epitopes in the neuronal pathology induced by the two strains differed qualitatively in the brain stem and the red nucleus. However, quantitative analysis of the positivity for the DAB-based chromogen in the brain stem and the red nucleus for the N-terminal-directed 2H6 and pS129-directed 81a antibodies did not reveal a significant difference. This may suggest that the pathology induced by $\alpha$-Syn PFF compared the $\alpha$-Syn/p25 $\alpha$ strain results in smaller aggregates that are more dispersed in the tissue and thus not appreciated by the qualitative inspection for more prominent cell body pathology.

To determine if we could find a biochemical or structural correlation of the aggregates or seeds in the tissue with the disease phenotype and inoculum of the strains, we conducted a series of experiments based on extracts 
of the pons and medulla oblongata of end-stage mice and age-matched healthy controls. First, we analysed the level of $\alpha$-Syn aggregates based on an immune-FRET assay and demonstrated a significantly higher level of aggregates in the $\alpha-S y n / p 25 \alpha$ strain induced mice that correlated with the stronger inclusion pathology. By contrast, the control $\alpha$-Syn strain induced a low response close to the absent signal in the negative control animals. The higher aggregate load in the $\alpha$-Syn/p25 $\alpha$ strain-induced mice resembles the higher load in brain homogenates from rats expressing human $\alpha$-Syn inoculated with MSA-derived strains compared to PD and DLB [106]. Second, using the PMCA technique, we amplified the seeds to demonstrate if the in vivo generated seeds retained structural and biochemical characteristics of the inoculated strains. Surprisingly, the analysis demonstrated that the seeding activity in the brain homogenates of the $\alpha-\operatorname{Syn} / \mathrm{p} 25 \alpha$ strain-induced animals was lower than in $\alpha$-Syn strain-induced mice as determined by diluting the brain homogenate. ThT analysis of the amplified aggregates demonstrated that the maximal signal of the plateau differed within the groups and did not allow us to discriminate between groups. Moreover, the proteinase K digestion pattern also differed within the groups and did not allow us to discriminate between groups. The ThT analysis was repeated on aggregates reamplified from the primary amplificates and demonstrated no difference between the two groups.

Hence, the aggressive disease phenotype correlated with the load of aggregates, but could not be associated with any of the structural characteristics we tested. This was not entirely surprising, because it has previously been demonstrated that transgenic M83 mice expressing human A53T$\alpha$-Syn generate only Campbell-Switzer-silver positive inclusions when inoculated with MSA brain extracts [55]. Since LB are only positive for Campbell-Switzer-silver staining, whereas CGI in human MSA tissue are positive for both Campbell-Switzer- and Gallyas-silver-staining, this suggests that human A53T- $\alpha$-Syn expressed by the mPrP promoter affects the fidelity of the templating.

Compared to the control $\alpha$-Syn polymorph, the $\alpha$-Syn/ p25 $\alpha$ strain exhibited a differential targeting in the CNS where especially the red nucleus and the reticular formation were affected. This suggests that the CNS spreading governed by $\alpha-S y n / p 25 \alpha$ seeds depends not just on the $\alpha$-Syn expression level and neuronal connectivity [39], but is also modulated by strain-dependent factors, e.g., binding of seeds to specific surface receptors [13, 63, 93]. Systematic investigations of ligands for aggregated and even pS129-phosphorylated $\alpha$-Syn have been conducted [8, 67], but $\alpha$-Syn strain-specific interactomes have still not been reported.

Prior studies of injection of human $\alpha$-syn PFF into the mouse striato-nigral system have resulted in small/moderate dopaminergic death in SN, with subtle-to-no motor defects $[60,76,81]$. However, murine $\alpha$-syn PFF injection can lead to neuronal dysfunction without significant cell death, but still induce relevant behavioural changes [99]. In wild-type mice, unilateral injection of the two strains into the striatum induced a hyperactivity that was detectable on the challenging beam after 6 months. In accordance with this, we have recently observed hyperactivity upon injection of murine $\alpha$-syn PFF into the striatum of rats [102]. Such hyperactivity has been previously described as an early sign of neurodegeneration in $\alpha$-Syn-transgenic mice and it is linked to increased dopamine in the striatum [52, 104], likely caused by disturbances in dopamine transporters in the nerve terminals [33]. The cylinder test allowed us to discriminate the two strains as early as 3 months after injection, where the $\alpha$-Syn/p25 $\alpha$ strain induced a stronger asymmetry of the use of the forelimbs that became apparent also in the hindlimbs at 6 months. Remarkably, the enhanced motor impairment of the $\alpha-S y n / p 25 \alpha$ strain was not associated with a wider $\alpha$-Syn aggregate pathology in the brain, but with a more localized $\alpha$-syn pathology in SN. The control $\alpha$-Syn strain induced a faster and more widespread development of inclusion pathology that was evident at 3 months in all regions connected to the striatum. By contrast, the $\alpha$-Syn $/ \mathrm{p} 25 \alpha$ strain primarily targeted the striatum (area of injection) and the SN but with a lower load of inclusions than the control strain at earlier time points. However, after 6 months, the pathology induced in striatum and SN by the control $\alpha$-Syn strains was almost completely resolved as previously reported [39], whereas the $\alpha$-Syn $/ \mathrm{p} 25 \alpha$-induced inclusions persisted in $\mathrm{SN}$. This may indicate that the neurons had more difficulty in resolving the $\alpha$-Syn $/ \mathrm{p} 25 \alpha$-induced aggregates and thus corroborates our observation of larger inclusions in the cell models. As previously shown, $\alpha$-Syn injections induced neuroinflammatory responses as revealed by the observed astrogliosis and microgliosis, as well as the MHCII upregulation, a key protein in PD immune response [37, 38, 102]. However, further suggesting a distinctive strain, this immune response was lower in the $\alpha$-Syn $/ \mathrm{p} 25 \alpha$ mice. Indeed, the different inflammatory capacity of $\alpha$-Syn has been associated with its aggregation and with mutations [24], which could affect its interaction with receptors, subsequent phagocytosis, and MHCII presentation by the microglia [24, 42]. This could explain the lower gliosis and MHCII expression and the trend to show less phagocytic marker CD68 in the $\alpha$-Syn/ p25 $\alpha$ group. However, the nigral loss of dopaminergic neurons after 6 months was comparable for the two strains. This suggests that the behavioural deficits induced by the $\alpha$-Syn/ p25 $\alpha$ strain were caused by neuronal dysfunctions rather than loss of neurons or inflammation-induced changes. The morphology of the neuronal inclusions induced by the two strains in the wild-type mice differed with the control $\alpha$-Syn strain inducing more skein-like inclusions often localised on one side of the nucleus like LB inclusions. By contrast, the $\alpha$-Syn/p25 $\alpha$ strain induced large spherical and ring-like 
inclusion in the SN pars compacta. Similar neuronal inclusions in the M83 line were recently reported using PFF amplified from brain tissue of MSA patients, spontaneously sick M83 mice and de novo generated PFF [54]. The morphology of the LB-like inclusion induced by our control PFF suggests that the neurons were able to sequester the templated $\alpha$-Syn aggregates in one area of the cell body. By contrast, the inclusions templated by the $\alpha-S y n / p 25 \alpha$ strain filled the entire cell body and suggests an inefficient cellular sequestering of the aggregates that potentially remain free to engage in more toxic interactions in the neuron. The $\alpha$-Syn/p25 $\alpha$-induced inclusions are reminiscent of the neuronal cytoplasmic $\alpha$-Syn inclusions in the limbic regions in atypical MSA patients [3] that correlate with cognitive impairment [69]. The disconnect between inclusion burden and dysfunctions in the wild-type mice inoculated with our two strains suggests the existence of templated aggregates that despite exerting toxic effects are not detectable with our current immunohistochemical techniques that preferentially detect inclusions. This is corroborated by the demonstration of abundant $\alpha$-Syn aggregate pathology in MSA detectable by the proximity ligation assay, which did not overlap with GCI detectable by immunohistochemistry $[82,90]$.

Our results demonstrate that the oligodendroglial protein p25 $\alpha$ can stimulate folding of an $\alpha$-Syn aggregate strain that in vivo templates neuronal $\alpha$-Syn aggregates with enhanced neurodegenerative potential as evidenced by earlier motoric dysfunctions and a more aggressive disease course. The interaction between $\mathrm{p} 25 \alpha$ and $\alpha$-Syn may represent a novel target in MSA and the in vitro generated $\alpha-S y n / p 25 \alpha$ polymorph, a novel tool for modelling synucleinopathies. There is no reason to expect this example of strain-specific folding dictated by a particular binding partner to be an isolated case. p25 $\alpha$ was originally identified in rat brain cytosolic extract through its ability to associate with $\alpha$-Syn aggregates [58], and co-aggregates of $\alpha$-Syn and tau can also seed $\alpha$-Syn aggregation in vivo albeit with less spreading of pathology compared to $\alpha$-Syn aggregates alone [113]. Insight into the cellular location and impact on aggregation of these proteins may open new perspectives in our understanding of strain development and how to combat this devastating class of diseases.

Supplementary Information The online version contains supplementary material available at https://doi.org/10.1007/s00401-021-02316-0.

Acknowledgements The study was supported by Lundbeck Foundation grants R223-2015-4222 for PHJ, R248-2016-2518 for Danish Research Institute of Translational Neuroscience-DANDRITE, Nordic-EMBL Partnership for Molecular Medicine, Aarhus University, Denmark, Postdoctoral Fellowship R171-2014-591 to N.F. and R276-2018-671 to D.E.O and J.S.N. The National Institutes of Health R01NS100876 to B.I.G., Danish Council for Independent Research Grant ID: 610800396B to M.D., a Predoctoral Fellowship F30AG063446 to Z.A.S. This work was funded in part by a grant from the Michael J Fox
Foundation for Parkinson's Research to C.S. The authors would like to thank Marie Vestergaard for graphical data analysis with $\mathrm{R}$ programming and Jette Bank Lauridsen and Gitte Ulberg Toft for excellent technical assistance.

Author contributions NF designed and performed most experiments, including PFF generation, sedimentation assays, K114 and ThT fluorometry, DLS, immunoblots, proteolytic digestion, oligodendrocyte cell cultures, designed and supervised in vivo experiments, performed intramuscular injections of PFF, mice behavioural analysis, assisted stereotaxic injections of PFF, analysed and interpreted the data, and wrote the manuscript. HG performed K114 and ThT fluorometry, DLS, proteolytic digestion and immunoblots, $\alpha$-Syn PFF generation. ZAS performed immunohistochemical analysis. EG performed oligodendrocyte cell culture and immunofluorescence microscopy analysis. SIS performed iPSCs-derived neuronal differentiation, cell culture, and immunofluorescence microscopy analysis, and MM interpreted the data. LR performed PFF sedimentation assays, K114 and ThT fluorometry, immunoblots, and proteolytic digestion. CB performed experiments. CPG performed behavioural and immunohistochemical analysis. MB performed immunohistochemical and stereological analysis. MN performed NMR analysis and UA interpreted the data. JW performed TEM and AFM analysis and MD interpreted the data. NM, PR, and MS performed the PMCA analysis of $\alpha$-Syn aggregates in mouse brain samples and proteinase $\mathrm{K}$ digestion analysis of amplified aggregates and MS and CS interpreted the data. KBA, KW, and EC performed the FRET-based Cisbio analysis and interpreted the data. JSN performed $\mathrm{CD}$ and FTIR analysis, and DEO interpreted the data. BIG provided the M83 mice and interpreted the immunohistochemical data. MRR designed and supervised in vivo experiments, performed stereotaxic injections of PFF, and interpreted the behaviour and immunohistochemistry data. PHJ designed experiments, supervised the study, interpreted the data, and wrote the manuscript.

Data availability The data that support the findings of this study are available from the corresponding authors upon reasonable request.

\section{Declarations}

Conflict of interest The authors declare no competing interests.

Open Access This article is licensed under a Creative Commons Attribution 4.0 International License, which permits use, sharing, adaptation, distribution and reproduction in any medium or format, as long as you give appropriate credit to the original author(s) and the source, provide a link to the Creative Commons licence, and indicate if changes were made. The images or other third party material in this article are included in the article's Creative Commons licence, unless indicated otherwise in a credit line to the material. If material is not included in the article's Creative Commons licence and your intended use is not permitted by statutory regulation or exceeds the permitted use, you will need to obtain permission directly from the copyright holder. To view a copy of this licence, visit http://creativecommons.org/licenses/by/4.0/.

\section{References}

1. Abdelmotilib H, Maltbie T, Delic V, Liu Z, Hu X, Fraser KB et al (2017) alpha-Synuclein fibril-induced inclusion spread in rats and mice correlates with dopaminergic Neurodegeneration. Neurobiol Dis 105:84-98. https://doi.org/10.1016/j.nbd.2017.05. 014 
2. Anderson JP, Walker DE, Goldstein JM, de Laat R, Banducci $\mathrm{K}$, Caccavello RJ et al (2006) Phosphorylation of Ser-129 is the dominant pathological modification of alpha-synuclein in familial and sporadic Lewy body disease. J Biol Chem 281:2973929752. https://doi.org/10.1074/jbc.M600933200

3. Aoki N, Boyer PJ, Lund C, Lin WL, Koga S, Ross OA et al (2015) Atypical multiple system atrophy is a new subtype of frontotemporal lobar degeneration: frontotemporal lobar degeneration associated with alpha-synuclein. Acta Neuropathol 130:93-105. https://doi.org/10.1007/s00401-015-1442-z

4. Asi YT, Simpson JE, Heath PR, Wharton SB, Lees AJ, Revesz $T$ et al (2014) Alpha-synuclein mRNA expression in oligodendrocytes in MSA. Glia 62:964-970. https://doi.org/10.1002/glia. 22653

5. Badiola N, de Oliveira RM, Herrera F, Guardia-Laguarta C, Goncalves SA, Pera M et al (2011) Tau enhances alpha-synuclein aggregation and toxicity in cellular models of synucleinopathy. PLoS ONE 6:e26609. https://doi.org/10.1371/journal.pone. 0026609

6. Baker KG, Huang Y, McCann H, Gai WP, Jensen PH, Halliday GM (2006) P25alpha immunoreactive but alpha-synuclein immunonegative neuronal inclusions in multiple system atrophy. Acta Neuropathol 111:193-195. https://doi.org/10.1007/ s00401-005-0008-x

7. Baldwin AJ, Knowles TP, Tartaglia GG, Fitzpatrick AW, Devlin GL, Shammas SL et al (2011) Metastability of native proteins and the phenomenon of amyloid formation. J Am Chem Soc 133:14160-14163. https://doi.org/10.1021/ja2017703

8. Betzer C, Movius AJ, Shi M, Gai WP, Zhang J, Jensen PH (2015) Identification of synaptosomal proteins binding to monomeric and oligomeric alpha-synuclein. PLoS ONE 10:e0116473. https://doi.org/10.1371/journal.pone.0116473

9. Bogetofte H, Jensen P, Ryding M, Schmidt SI, Okarmus J, Ritter L et al (2019) PARK2 Mutation Causes Metabolic Disturbances and Impaired Survival of Human iPSC-Derived Neurons. Front Cell Neurosci 13:297. https://doi.org/10.3389/fncel.2019.00297

10. Bousset L, Pieri L, Ruiz-Arlandis G, Gath J, Jensen PH, Habenstein B et al (2013) Structural and functional characterization of two alpha-synuclein strains. Nat Commun 4:2575. https://doi. org/10.1038/ncomms 3575

11. Braak H, Rub U, Gai WP, Del Tredici K (2003) Idiopathic Parkinson's disease: possible routes by which vulnerable neuronal types may be subject to neuroinvasion by an unknown pathogen. J Neural Transm 110:517-536. https://doi.org/10.1007/ s00702-002-0808-2

12. Burre J, Sharma M, Tsetsenis T, Buchman V, Etherton MR, Sudhof TC (2010) Alpha-synuclein promotes SNARE-complex assembly in vivo and in vitro. Science 329:1663-1667. https:// doi.org/10.1126/science.1195227

13. Choi YR, Cha SH, Kang SJ, Kim JB, Jou I, Park SM (2018) Prion-like Propagation of alpha-Synuclein Is Regulated by the FcgammaRIIB-SHP-1/2 Signaling Pathway in Neurons. Cell Rep 22:136-148. https://doi.org/10.1016/j.celrep.2017.12.009

14. Crystal AS, Giasson BI, Crowe A, Kung MP, Zhuang ZP, Trojanowski JQ et al (2003) A comparison of amyloid fibrillogenesis using the novel fluorescent compound K114. J Neurochem 86:1359-1368

15. Dhillon JS, Riffe C, Moore BD, Ran Y, Chakrabarty P, Golde TE et al (2017) A novel panel of alpha-synuclein antibodies reveal distinctive staining profiles in synucleinopathies. PLoS ONE 12:e0184731. https://doi.org/10.1371/journal.pone.0184731

16. Dhillon JS, Trejo-Lopez JA, Riffe C, McFarland NR, Hiser WM, Giasson BI et al (2019) Dissecting alpha-synuclein inclusion pathology diversity in multiple system atrophy: implications for the prion-like transmission hypothesis. Lab Invest. https://doi. org/10.1038/s41374-019-0198-9
17. Dickson DW, Liu W, Hardy J, Farrer M, Mehta N, Uitti R et al (1999) Widespread alterations of alpha-synuclein in multiple system atrophy. Am J Pathol 155:1241-1251

18. Djelloul M, Holmqvist S, Boza-Serrano A, Azevedo C, Yeung MS, Goldwurm S et al (2015) Alpha-Synuclein Expression in the Oligodendrocyte Lineage: an In Vitro and In Vivo Study Using Rodent and Human Models. Stem Cell Rep 5:174-184. https://doi.org/10.1016/j.stemcr.2015.07.002

19. Duda JE, Giasson BI, Gur TL, Montine TJ, Robertson D, Biaggioni I et al (2000) Immunohistochemical and biochemical studies demonstrate a distinct profile of alpha-synuclein permutations in multiple system atrophy. J Neuropathol Exp Neurol 59:830-841

20. Duda JE, Giasson BI, Mabon ME, Lee VM, Trojanowski JQ (2002) Novel antibodies to synuclein show abundant striatal pathology in Lewy body diseases. Ann Neurol 52:205-210. https://doi.org/10.1002/ana.10279

21. Ejlerskov P, Rasmussen I, Nielsen TT, Bergstrom AL, Tohyama Y, Jensen PH et al (2013) Tubulin polymerization-promoting protein (TPPP/p25alpha) promotes unconventional secretion of alpha-synuclein through exophagy by impairing autophagosome-lysosome fusion. J Biol Chem 288:1731317335. https://doi.org/10.1074/jbc.M112.401174

22. Elfarrash S, Jensen NM, Ferreira N, Betzer C, Thevathasan JV, Diekmann R et al (2019) Organotypic slice culture model demonstrates inter-neuronal spreading of alpha-synuclein aggregates. Acta Neuropathol Commun 7:213. https://doi.org/10. 1186/s40478-019-0865-5

23. Ferreira N, Goncalves NP, Jan A, Jensen NM, van der Laan A, Mohseni S et al (2021) Trans-synaptic spreading of alpha-synuclein pathology through sensory afferents leads to sensory nerve degeneration and neuropathic pain. Acta Neuropathol Commun 9:31. https://doi.org/10.1186/s40478-021-01131-8

24. Ferreira SA, Romero-Ramos M (2018) Microglia response during Parkinson's disease: alpha-synuclein intervention. Front Cell Neurosci 12:247. https://doi.org/10.3389/fncel.2018.00247

25. Fleming SM, Ekhator OR, Ghisays V (2013) Assessment of sensorimotor function in mouse models of Parkinson's disease. J Vis Exp. https://doi.org/10.3791/50303

26. Fujiwara H, Hasegawa M, Dohmae N, Kawashima A, Masliah E, Goldberg MS et al (2002) alpha-Synuclein is phosphorylated in synucleinopathy lesions. Nat Cell Biol 4:160-164. https://doi. org/10.1038/ncb748

27. Gai WP, Power JH, Blumbergs PC, Blessing WW (1998) Multiple-system atrophy: a new alpha-synuclein disease? Lancet 352:547-548. https://doi.org/10.1016/s0140-6736(05)79256-4

28. Gath J, Bousset L, Habenstein B, Melki R, Meier BH, Bockmann A (2014) Yet another polymorph of alpha-synuclein: solid-state sequential assignments. Biomol NMR Assign 8:395-404. https:// doi.org/10.1007/s12104-013-9526-y

29. Gath J, Habenstein B, Bousset L, Melki R, Meier BH, Bockmann A (2012) Solid-state NMR sequential assignments of alpha-synuclein. Biomol NMR Assign 6:51-55. https://doi.org/ 10.1007/s12104-011-9324-3

30. Giasson BI, Forman MS, Higuchi M, Golbe LI, Graves CL, Kotzbauer PT (2003) Initiation and synergistic fibrillization of tau and alpha-synuclein. Science 300:636-640. https://doi.org/10.1126/ science. 1082324

31. Goedert M, Jakes R, Spillantini MG (2017) The synucleinopathies: twenty years on. J Parkinsons Dis 7:S51-S69. https://doi. org/10.3233/JPD-179005

32. Goldbaum O, Jensen PH, Richter-Landsberg C (2008) The Expression of Tubulin Polymerization Promoting Protein TPPP/ p25 alpha is Developmentally Regulated in Cultured Rat Brain Oligodendrocytes and Affected by Proteolytic Stress. Glia 56:1736-1746. https://doi.org/10.1002/glia.20720 
33. Graham DR, Sidhu A (2010) Mice expressing the A53T mutant form of human alpha-synuclein exhibit hyperactivity and reduced anxiety-like behavior. J Neurosci Res 88:1777-1783. https://doi. org/10.1002/jnr.22331

34. Gribaudo S, Tixador P, Bousset L, Fenyi A, Lino P, Melki R et al (2019) Propagation of alpha-synuclein strains within human reconstructed neuronal network. Stem Cell Rep 12:230-244. https://doi.org/10.1016/j.stemcr.2018.12.007

35. Guyenet SJ, Furrer SA, Damian VM, Baughan TD, La Spada AR, Garden GA (2010) A simple composite phenotype scoring system for evaluating mouse models of cerebellar ataxia. J Vis Exp. https://doi.org/10.3791/1787

36. Halliday GM, Holton JL, Revesz T, Dickson DW (2011) Neuropathology underlying clinical variability in patients with synucleinopathies. Acta Neuropathol 122:187-204. https://doi.org/ 10.1007/s00401-011-0852-9

37. Harms AS, Cao SW, Rowse AL, Thome AD, Li XR, Mangieri LR et al (2013) MHCII is required for alpha-synuclein-induced activation of microglia, CD4 T Cell proliferation, and dopaminergic neurodegeneratione. J Neurosci 33:9592-9600. https://doi. org/10.1523/Jneurosci.5610-12.2013

38. Harms AS, Delic V, Thome AD, Bryant N, Liu Z, Chandra S et al (2017) alpha-Synuclein fibrils recruit peripheral immune cells in the rat brain prior to neurodegeneration. Acta Neuropathol Commun 5:85. https://doi.org/10.1186/s40478-017-0494-9

39. Henderson MX, Cornblath EJ, Darwich A, Zhang B, Brown H, Gathagan RJ et al (2019) Spread of alpha-synuclein pathology through the brain connectome is modulated by selective vulnerability and predicted by network analysis. Nat Neurosci 22:12481257. https://doi.org/10.1038/s41593-019-0457-5

40. Hernandez DG, Reed X, Singleton AB (2016) Genetics in Parkinson disease: mendelian versus non-mendelian inheritance. J Neurochem 139(Suppl 1):59-74. https://doi.org/10.1111/jnc. 13593

41. Jan A, Jansonius B, Delaidelli A, Bhanshali F, An YA, Ferreira $\mathrm{N}$ et al (2018) Activity of translation regulator eukaryotic elongation factor-2 kinase is increased in Parkinson disease brain and its inhibition reduces alpha synuclein toxicity. Acta Neuropathol Commun 6:54. https://doi.org/10.1186/s40478-018-0554-9

42. Juul-Madsen K, Qvist P, Bendtsen KL, Langkilde AE, Vestergaard B, Howard KA et al (2020) Size-selective phagocytic clearance of fibrillar alpha-synuclein through conformational activation of complement receptor 4. J Immunol 204:1345-1361. https://doi.org/10.4049/jimmunol.1900494

43. Kaji S, Maki T, Ishimoto T, Yamakado H, Takahashi R (2020) Insights into the pathogenesis of multiple system atrophy: focus on glial cytoplasmic inclusions. Transl Neurodegener. https://doi. org/10.1186/s40035-020-0185-5 ((ARTN7))

44. Kaji S, Maki T, Kinoshita H, Uemura N, Ayaki T, Kawamoto Y et al (2018) Pathological endogenous alpha-synuclein accumulation in oligodendrocyte precursor cells potentially induces inclusions in multiple system atrophy. Stem Cell Reports 10:356-365. https://doi.org/10.1016/j.stemcr.2017.12.001

45. Kaji S, Maki T, Ueda J, Ishimoto T, Inoue Y, Yasuda K et al (2020) BCAS1-positive immature oligodendrocytes are affected by the alpha-synuclein-induced pathology of multiple system atrophy. Acta Neuropathol Commun 8:120. https://doi.org/10. 1186/s40478-020-00997-4

46. Kiely AP, Asi YT, Kara E, Limousin P, Ling H, Lewis P et al (2013) alpha-Synucleinopathy associated with G51D SNCA mutation: a link between Parkinson's disease and multiple system atrophy? Acta Neuropathol 125:753-769. https://doi.org/10. 1007/s00401-013-1096-7

47. Kirik D, Rosenblad C, Burger C, Lundberg C, Johansen TE, Muzyczka N et al (2002) Parkinson-like neurodegeneration induced by targeted overexpression of alpha-synuclein in the nigrostriatal system. J Neurosci 22:2780-2791.

48. Kordower JH, Chu Y, Hauser RA, Freeman TB, Olanow CW (2008) Lewy body-like pathology in long-term embryonic nigral transplants in Parkinson's disease. Nat Med 14:504-506. https://doi.org/10.1038/nm1747

49. Kovacs GG, Laszlo L, Kovacs J, Jensen PH, Lindersson E, Botond G et al (2004) Natively unfolded tubulin polymerization promoting protein TPPP/p25 is a common marker of alpha-synucleinopathies. Neurobiol Dis 17:155-162. https:// doi.org/10.1016/j.nbd.2004.06.006

50. Kragh CL, Fillon G, Gysbers A, Hansen HD, Neumann M, Richter-Landsberg C et al (2013) FAS-dependent cell death in alpha-synuclein transgenic oligodendrocyte models of multiple system atrophy. PLoS ONE 8:e55243. https://doi.org/10.1371/ journal.pone.0055243

51. Kragh CL, Gysbers AM, Rockenstein E, Murphy K, Halliday GM, Masliah E et al (2014) Prodegenerative IkappaBalpha expression in oligodendroglial alpha-synuclein models of multiple system atrophy. Neurobiol Dis 63:171-183. https://doi.org/ 10.1016/j.nbd.2013.12.002

52. Kragh CL, Lund LB, Febbraro F, Hansen HD, Gai WP, El-Agnaf $\mathrm{O}$ et al (2009) Alpha-synuclein aggregation and Ser-129 phosphorylation-dependent cell death in oligodendroglial cells. J Biol Chem 284:10211-10222. https://doi.org/10.1074/jbc.M8096 71200

53. Lam HA, Wu N, Cely I, Kelly RL, Hean S, Richter F et al (2011) Elevated tonic extracellular dopamine concentration and altered dopamine modulation of synaptic activity precede dopamine loss in the striatum of mice overexpressing human alpha-synuclein. J Neurosci Res 89:1091-1102. https://doi.org/10.1002/jnr.22611

54. Lassen LB, Gregersen E, Isager AK, Betzer C, Kofoed RH, Jensen PH (2018) ELISA method to detect alpha-synuclein oligomers in cell and animal models. PLoS ONE 13:e0196056. https://doi.org/10.1371/journal.pone.0196056

55. Lau A, So RWL, Lau HHC, Sang JC, Ruiz-Riquelme A, Fleck SC et al (2020) alpha-Synuclein strains target distinct brain regions and cell types. Nat Neurosci 23:21-31. https://doi.org/10.1038/ s41593-019-0541-x

56. Lavenir I, Passarella D, Masuda-Suzukake M, Curry A, Holton JL, Ghetti B et al (2019) Silver staining (Campbell-Switzer) of neuronal alpha-synuclein assemblies induced by multiple system atrophy and Parkinson's disease brain extracts in transgenic mice. Acta Neuropathol Commun 7:148. https://doi.org/10.1186/ s40478-019-0804-5

57. Li JY, Englund E, Holton JL, Soulet D, Hagell P, Lees AJ et al (2008) Lewy bodies in grafted neurons in subjects with Parkinson's disease suggest host-to-graft disease propagation. Nat Med 14:501-503. https://doi.org/10.1038/nm1746

58. Lindersson E, Beedholm R, Hojrup P, Moos T, Gai W, Hendil $\mathrm{KB}$ et al (2004) Proteasomal inhibition by alpha-synuclein filaments and oligomers. J Biol Chem 279:12924-12934. https://doi. org/10.1074/jbc.M306390200

59. Lindersson E, Lundvig D, Petersen C, Madsen P, Nyengaard JR, Hojrup P, Moos T et al (2005) p25alpha Stimulates alphasynuclein aggregation and is co-localized with aggregated alphasynuclein in alpha-synucleinopathies. J Biol Chem 280:57035715. https://doi.org/10.1074/jbc.M410409200

60. Lindersson EK, Hojrup P, Gai WP, Locker D, Martin D, Jensen PH (2004) alpha-Synuclein filaments bind the transcriptional regulator HMGB-1. NeuroReport 15:2735-2739

61. Luk KC, Covell DJ, Kehm VM, Zhang B, Song IY, Byrne MD et al (2016) Molecular and biological compatibility with host alpha-synuclein influences fibril pathogenicity. Cell Rep 16:3373-3387. https://doi.org/10.1016/j.celrep.2016.08.053 
62. Luk KC, Kehm V, Carroll J, Zhang B, O’Brien P, Trojanowski JQ et al (2012) Pathological alpha-synuclein transmission initiates Parkinson-like neurodegeneration in nontransgenic mice. Science 338:949-953. https://doi.org/10.1126/science.1227157

63. Luk KC, Kehm VM, Zhang B, O’Brien P, Trojanowski JQ, Lee VM (2012) Intracerebral inoculation of pathological alphasynuclein initiates a rapidly progressive neurodegenerative alphasynucleinopathy in mice. J Exp Med 209:975-986. https://doi. org/10.1084/jem.20112457

64. Mao X, Ou MT, Karuppagounder SS, Kam TI, Yin X, Xiong Y et al (2016) Pathological alpha-synuclein transmission initiated by binding lymphocyte-activation gene 3 . Science. https://doi. org/10.1126/science.aah3374

65. Martinez-Vicente M, Talloczy Z, Kaushik S, Massey AC, Mazzulli J, Mosharov EV et al (2008) Dopamine-modified alphasynuclein blocks chaperone-mediated autophagy. J Clin Invest 118:777-788. https://doi.org/10.1172/JCI32806

66. Mavroeidi P, Arvanitaki F, Karakitsou AK, Vetsi M, Kloukina I, Zweckstetter M et al (2019) Endogenous oligodendroglial alpha-synuclein and TPPP/p25alpha orchestrate alpha-synuclein pathology in experimental multiple system atrophy models. Acta Neuropathol 138:415-441. https://doi.org/10.1007/ s00401-019-02014-y

67. McCann H, Cartwright H, Halliday GM (2016) Neuropathology of alpha-synuclein propagation and braak hypothesis. Mov Disord 31:152-160. https://doi.org/10.1002/mds.26421

68. McFarland MA, Ellis CE, Markey SP, Nussbaum RL (2008) Proteomics analysis identifies phosphorylation-dependent alphasynuclein protein interactions. Mol Cell Proteomics 7:21232137. https://doi.org/10.1074/mcp.M800116-MCP200

69. Micsonai A, Wien F, Kernya L, Lee YH, Goto Y, Refregiers M et al (2015) Accurate secondary structure prediction and fold recognition for circular dichroism spectroscopy. Proc Natl Acad Sci USA 112:E3095-3103. https://doi.org/10.1073/pnas. 15008 51112

70. Miki Y, Foti SC, Hansen D, Strand KM, Asi YT, Tsushima E et al (2020) Hippocampal alpha-synuclein pathology correlates with memory impairment in multiple system atrophy. Brain 143:1798-1810. https://doi.org/10.1093/brain/awaa126

71. Miller DW, Johnson JM, Solano SM, Hollingsworth ZR, Standaert DG, Young AB (2005) Absence of alpha-synuclein mRNA expression in normal and multiple system atrophy oligodendroglia. J Neural Transm (Vienna) 112:1613-1624. https://doi.org/ 10.1007/s00702-005-0378-1

72. Monzio Compagnoni G, Di Fonzo A (2019) Understanding the pathogenesis of multiple system atrophy: state of the art and future perspectives. Acta Neuropathol Commun 7:113. https:// doi.org/10.1186/s40478-019-0730-6

73. O’Nuallain B, Shivaprasad S, Kheterpal I, Wetzel R (2005) Thermodynamics of A beta(1-40) amyloid fibril elongation. Biochemistry 44:12709-12718. https://doi.org/10.1021/bi050 927h

74. Okarmus J, Bogetofte H, Schmidt SI, Ryding M, Garcia-Lopez S, Ryan BJ (2020) Lysosomal perturbations in human dopaminergic neurons derived from induced pluripotent stem cells with PARK2 mutation. Sci Rep 10:10278. https://doi.org/10.1038/ s41598-020-67091-6

75. Ota K, Obayashi M, Ozaki K, Ichinose S, Kakita A, Tada M et al (2014) Relocation of $\mathrm{p} 25 \mathrm{alpha/tubulin}$ polymerization promoting protein from the nucleus to the perinuclear cytoplasm in the oligodendroglia of sporadic and COQ2 mutant multiple system atrophy. Acta Neuropathol Commun 2:136. https://doi.org/10. 1186/s40478-014-0136-4

76. Pasanen P, Myllykangas L, Siitonen M, Raunio A, Kaakkola S, Lyytinen J et al (2014) Novel alpha-synuclein mutation A53E associated with atypical multiple system atrophy and Parkinson's disease-type pathology. Neurobiol Aging 35(2180):e2181-2185. https://doi.org/10.1016/j.neurobiolaging.2014.03.024

77. Peelaerts W, Bousset L, Van der Perren A, Moskalyuk A, Pulizzi R, Giugliano M et al (2015) alpha-Synuclein strains cause distinct synucleinopathies after local and systemic administration. Nature 522:340-344. https://doi.org/10.1038/nature14547

78. Peng C, Gathagan RJ, Covell DJ, Medellin C, Stieber A, Robinson JL et al (2018) Cellular milieu imparts distinct pathological alpha-synuclein strains in alpha-synucleinopathies. Nature 557:558-563. https://doi.org/10.1038/s41586-018-0104-4

79. Piras IS, Bleul C, Schrauwen I, Talboom J, Llaci L, De Both MD et al (2020) Transcriptional profiling of multiple system atrophy cerebellar tissue highlights differences between the parkinsonian and cerebellar sub-types of the disease. Acta Neuropathol Com. https://doi.org/10.1186/s40478-020-00950-5

80. Prusiner SB, Woerman AL, Mordes DA, Watts JC, Rampersaud R, Berry DB et al (2015) Evidence for alpha-synuclein prions causing multiple system atrophy in humans with parkinsonism. Proc Natl Acad Sci USA 112:E5308-5317. https://doi.org/10. 1073/pnas. 1514475112

81. Rannikko EH, Vesterager LB, Shaik JH, Weber SS, Cornejo Castro EM, Fog K et al (2013) Loss of DJ-1 protein stability and cytoprotective function by Parkinson's disease-associated proline-158 deletion. J Neurochem 125:314-327. https://doi.org/ $10.1111 /$ jnc. 12126

82. Rey NL, Steiner JA, Maroof N, Luk KC, Madaj Z, Trojanowski JQ et al (2016) Widespread transneuronal propagation of alphasynucleinopathy triggered in olfactory bulb mimics prodromal Parkinson's disease. J Exp Med 213:1759-1778. https://doi.org/ 10.1084/jem.20160368

83. Roberts RF, Wade-Martins R, Alegre-Abarrategui J (2015) Direct visualization of alpha-synuclein oligomers reveals previously undetected pathology in Parkinson's disease brain. Brain 138:1642-1657. https://doi.org/10.1093/brain/awv040

84. Rohan Z, Milenkovic I, Lutz MI, Matej R, Kovacs GG (2016) Shared and distinct patterns of oligodendroglial response in alpha-synucleinopathies and tauopathies. J Neuropathol Exp Neurol 75:1100-1109. https://doi.org/10.1093/jnen/nlw087

85. Rutherford NJ, Brooks M, Giasson BI (2016) Novel antibodies to phosphorylated alpha-synuclein serine 129 and NFL serine 473 demonstrate the close molecular homology of these epitopes. Acta Neuropathol Commun 4:80. https://doi.org/10. 1186/s40478-016-0357-9

86. Sacino AN, Ayers JI, Brooks MM, Chakrabarty P, Hudson VJ 3rd, Howard JK et al (2016) Non-prion-type transmission in A53T alpha-synuclein transgenic mice: a normal component of spinal homogenates from naive non-transgenic mice induces robust alpha-synuclein pathology. Acta Neuropathol 131:151154. https://doi.org/10.1007/s00401-015-1505-1

87. Sacino AN, Brooks M, Thomas MA, McKinney AB, Lee S, Regenhardt RW et al (2014) Intramuscular injection of alphasynuclein induces CNS alpha-synuclein pathology and a rapidonset motor phenotype in transgenic mice. Proc Natl Acad Sci USA 111:10732-10737. https://doi.org/10.1073/pnas.13217 85111

88. Sampson TR, Challis C, Jain N, Moiseyenko A, Ladinsky MS, Shastri GG et al (2020) A gut bacterial amyloid promotes alphasynuclein aggregation and motor impairment in mice. Elife. https://doi.org/10.7554/eLife.53111

89. Sampson TR, Debelius JW, Thron T, Janssen S, Shastri GG, Ilhan ZE et al (2016) Gut microbiota regulate motor deficits and neuroinflammation in a model of Parkinson's disease. Cell 167(1469-1480):e1412. https://doi.org/10.1016/j.cell.2016.11. 018

90. Schweighauser M, Shi Y, Tarutani A, Kametani F, Murzin AG, Ghetti B et al (2020) Structures of alpha-synuclein filaments 
from multiple system atrophy. Nature. https://doi.org/10.1038/ s41586-020-2317-6

91. Sekiya H, Kowa H, Koga H, Takata M, Satake W, Futamura $\mathrm{N}$ et al (2019) Wide distribution of alpha-synuclein oligomers in multiple system atrophy brain detected by proximity ligation. Acta Neuropathol 137:455-466. https://doi.org/10.1007/ s00401-019-01961-w

92. Sengupta U, Puangmalai N, Bhatt N, Garcia S, Zhao Y, Kayed R (2020) Polymorphic alpha-synuclein strains modified by dopamine and docosahexaenoic acid interact differentially with tau protein. Mol Neurobiol 57:2741-2765. https://doi.org/10.1007/ s12035-020-01913-6

93. Shahnawaz M, Mukherjee A, Pritzkow S, Mendez N, Rabadia P, Liu X et al (2020) Discriminating alpha-synuclein strains in Parkinson's disease and multiple system atrophy. Nature 578:273277. https://doi.org/10.1038/s41586-020-1984-7

94. Shrivastava AN, Bousset L, Renner M, Redeker V, Savistchenko J, Triller A et al (2020) Differential membrane binding and seeding of distinct alpha-synuclein fibrillar polymorphs. Biophys $\mathbf{J}$ 118:1301-1320. https://doi.org/10.1016/j.bpj.2020.01.022

95. Song YJ, Lundvig DM, Huang Y, Gai WP, Blumbergs PC, Hojrup P et al (2007) p25alpha relocalizes in oligodendroglia from myelin to cytoplasmic inclusions in multiple system atrophy. Am J Pathol 171:1291-1303. https://doi.org/10.2353/ajpath. 2007.070201

96. Sorrentino ZA, Xia Y, Funk C, Riffe CJ, Rutherford NJ, Ceballos Diaz C et al (2018) Motor neuron loss and neuroinflammation in a model of alpha-synuclein-induced neurodegeneration. Neurobiol Dis 120:98-106. https://doi.org/10.1016/j.nbd.2018.09.005

97. Spillantini MG, Crowther RA, Jakes R, Cairns NJ, Lantos PL, Goedert M (1998) Filamentous alpha-synuclein inclusions link multiple system atrophy with Parkinson's disease and dementia with Lewy bodies. Neurosci Lett 251:205-208

98. Stefanova N, Bucke P, Duerr S, Wenning GK (2009) Multiple system atrophy: an update. Lancet Neurol 8:1172-1178. https:// doi.org/10.1016/S1474-4422(09)70288-1

99. Stefanova N, Reindl M, Neumann M, Kahle PJ, Poewe W, Wenning GK (2007) Microglial activation mediates neurodegeneration related to oligodendroglial alpha-synucleinopathy: implications for multiple system atrophy. Mov Disord 22:2196-2203. https://doi.org/10.1002/mds.21671

100. Stoyka LE, Arrant AE, Thrasher DR, Russell DL, Freire J, Mahoney CL, Narayanan A, Dib AG, Standaert DG, Volpicelli-Daley LA (2020) Behavioral defects associated with amygdala and cortical dysfunction in mice with seeded alphasynuclein inclusions. Neurobiol Dis. https://doi.org/10.16/j. nbd.2019.104708 ((ARTN104708))

101. Strang KH, Goodwin MS, Riffe C, Moore BD, Chakrabarty P et al (2017) Generation and characterization of new monoclonal antibodies targeting the PHF1 and AT8 epitopes on human tau. Acta Neuropathol Commun 5:58. https://doi.org/10.1186/ s40478-017-0458-0

102. Strohaker T, Jung BC, Liou SH, Fernandez CO, Riedel D, Becker S et al (2019) Structural heterogeneity of alpha-synuclein fibrils amplified from patient brain extracts. Nat Commun 10:5535. https://doi.org/10.1038/s41467-019-13564-w

103. Sulzer D, Edwards RH (2019) The physiological role of alphasynuclein and its relationship to Parkinson's Disease. J Neurochem 150:475-486. https://doi.org/10.1111/jnc.14810

104. Thomsen MB, Ferreira SA, Schacht AC, Jacobsen J, Simonsen M, Betzer C et al (2021) PET imaging reveals early and progressive dopaminergic deficits after intra-striatal injection of preformed alpha-synuclein fibrils in rats. Neurobiol Dis 149:105229. https://doi.org/10.1016/j.nbd.2020.105229

105. Tuttle MD, Comellas G, Nieuwkoop AJ, Covell DJ, Berthold DA, Kloepper KD et al (2016) Solid-state NMR structure of a pathogenic fibril of full-length human alpha-synuclein. Nat Struct Mol Biol 23:409-415. https://doi.org/10.1038/nsmb. 3194

106. Unger EL, Eve DJ, Perez XA, Reichenbach DK, Xu Y, Lee MK et al (2006) Locomotor hyperactivity and alterations in dopamine neurotransmission are associated with overexpression of A53T mutant human alpha-synuclein in mice. Neurobiol Dis 21:431-443. https://doi.org/10.1016/j.nbd.2005.08.005

107. Van Den Berge N, Ferreira N, Gram H, Mikkelsen TW, Alstrup AKO, Casadei N et al (2019) Evidence for bidirectional and trans-synaptic parasympathetic and sympathetic propagation of alpha-synuclein in rats. Acta Neuropathol 138:535-550. https:// doi.org/10.1007/s00401-019-02040-w

108. Van der Perren A, Gelders G, Fenyi A, Bousset L, Brito F, Peelaerts W et al (2020) The structural differences between patient-derived alpha-synuclein strains dictate characteristics of Parkinson's disease, multiple system atrophy and dementia with Lewy bodies. Acta Neuropathol 139:977-1000. https://doi.org/ 10.1007/s00401-020-02157-3

109. Verasdonck J, Bousset L, Gath J, Melki R, Bockmann A, Meier BH (2016) Further exploration of the conformational space of alpha-synuclein fibrils: solid-state NMR assignment of a high-pH polymorph. Biomol NMR Assign 10:5-12. https://doi.org/10. 1007/s12104-015-9628-9

110. Watts JC, Giles K, Oehler A, Middleton L, Dexter DT, Gentleman SM et al (2013) Transmission of multiple system atrophy prions to transgenic mice. Proc Natl Acad Sci USA 110:1955519560. https://doi.org/10.1073/pnas.1318268110

111. Waxman EA, Duda JE, Giasson BI (2008) Characterization of antibodies that selectively detect alpha-synuclein in pathological inclusions. Acta Neuropathol 116:37-46. https://doi.org/10.1007/ s00401-008-0375-1

112. Waxman EA, Giasson BI (2008) Specificity and regulation of casein kinase-mediated phosphorylation of alpha-synuclein. J Neuropathol Exp Neurol 67:402-416. https://doi.org/10.1097/ NEN.0b013e31816fc995

113. Waxman EA, Mazzulli JR, Giasson BI (2009) Characterization of hydrophobic residue requirements for alpha-synuclein fibrillization. Biochemistry 48:9427-9436. https://doi.org/10.1021/bi900 $539 \mathrm{p}$

114. Wenning GK, Tison F, Ben Shlomo Y, Daniel SE, Quinn NP (1997) Multiple system atrophy: a review of 203 pathologically proven cases. Mov Disord 12:133-147. https://doi.org/10.1002/ mds. 870120203

115. Williams T, Sorrentino Z, Weinrich M, Giasson BI, Chakrabarty P (2020) Differential cross-seeding properties of tau and alphasynuclein in mouse models of tauopathy and synucleinopathy. Brain Commun 2:fcaa090. https://doi.org/10.1093/braincomms/ fcaa090

116. Woerman AL, Kazmi SA, Patel S, Freyman Y, Oehler A, Aoyagi A et al (2018) MSA prions exhibit remarkable stability and resistance to inactivation. Acta Neuropathol 135:49-63. https:// doi.org/10.1007/s00401-017-1762-2

117. Woerman AL, Oehler A, Kazmi SA, Lee J, Halliday GM, Middleton LT et al (2019) Multiple system atrophy prions retain strain specificity after serial propagation in two different $\operatorname{Tg}\left(\mathrm{SNCA}^{*} \mathrm{~A} 53 \mathrm{~T}\right)$ mouse lines. Acta Neuropathol 137:437-454. https://doi.org/10.1007/s00401-019-01959-4

118. Yamasaki TR, Holmes BB, Furman JL, Dhavale DD, Su BW, Song ES et al (2019) Parkinson's disease and multiple system atrophy have distinct alpha-synuclein seed characteristics. J Biol Chem 294:1045-1058. https://doi.org/10.1074/jbc.RA118. 004471

119. Zandomeneghi G, Krebs MR, McCammon MG, Fandrich M (2004) FTIR reveals structural differences between native 
beta-sheet proteins and amyloid fibrils. Protein Sci 13:3314-

3321. https://doi.org/10.1110/ps.041024904

Publisher's Note Springer Nature remains neutral with regard to jurisdictional claims in published maps and institutional affiliations.

\section{Authors and Affiliations}

\section{Nelson Ferreira ${ }^{1}$ (D Hjalte Gram ${ }^{1} \cdot$ Zachary A. Sorrentino $^{2} \cdot$ Emil Gregersen $^{1} \cdot$ Sissel Ida Schmidt $^{3}$ - Lasse Reimer ${ }^{1}$. Cristine Betzer ${ }^{1} \cdot$ Clara Perez-Gozalbo $^{1}$ - Marjo Beltoja ${ }^{1} \cdot$ Madhu Nagaraj $^{4} \cdot$ Jie Wang $^{4,5}$. Jan S. Nowak ${ }^{4}$. Mingdong Dong ${ }^{4} \cdot$ Katarina Willén $^{6} \cdot$ Ersoy Cholak $^{6} \cdot$ Kaare Bjerregaard-Andersen $^{6} \cdot$ Nicolas Mendez $^{7}$. Prakruti Rabadia ${ }^{7}$. Mohammad Shahnawaz ${ }^{7}$. Claudio Soto ${ }^{7}$. Daniel E. Otzen ${ }^{4}$. Ümit Akbey ${ }^{4,8,9} \cdot$ Morten Meyer $^{3,10}$. Benoit I. Giasson ${ }^{2} \cdot$ Marina Romero-Ramos ${ }^{1} \cdot$ Poul Henning Jensen ${ }^{1}$ (i)}

1 DANDRITE, Danish Research Institute of Translational Neuroscience \& Department of Biomedicine, Aarhus University, 8000 Aarhus C, Denmark

2 Department of Neuroscience, Center for Translational Research in Neurodegenerative Diseases and McKnight Brain Institute, University of Florida, Gainesville, USA

3 Department of Neurobiology Research, Institute of Molecular Medicine, University of Southern Denmark, J.B. Winsloews Vej 21, st, 5000 Odense C, Denmark

4 Interdisciplinary Nanoscience Center (iNANO), Aarhus University, 8000 Aarhus C, Denmark

5 Institute for Advanced Materials, School of Material Science and Engineering, Jiangsu University, Zhenjiang 212013, China
6 Department of Cell Biology, H. Lundbeck A/S, Valby, Denmark

$7 \quad$ Mitchell Center for Alzheimer's Disease and Related Brain Disorders, Department of Neurology, University of Texas McGovern Medical School At Houston, Houston, TX, USA

8 Aarhus Institute of Advanced Studies (AIAS), Aarhus University, 8000 Aarhus C, Denmark

9 Institute of Complex Systems (ICS6), Structural Biochemistry, Research Center Julich, 52415 Julich, Germany

10 BRIDGE, Brain Research, Inter-Disciplinary Guided Excellence, Department of Clinical Research, University of Southern Denmark, J.B. Winsloews Vej 19, 5000 Odense C, Denmark 